\title{
Risk shocks and housing supply: A quantitative analysis
}

\author{
Victor Dorofeenko ${ }^{a}$, Gabriel S. Lee ${ }^{\mathrm{b}, \mathrm{c}, 1}$, Kevin D. Salyer ${ }^{\mathrm{d}, *}$ \\ a Department of Economics and Finance, Institute for Advanced Studies, Stumpergasse 56, A-1060 Vienna, Austria \\ b IREBS, University of Regensburg, Universitaetstrasse 31, 93053 Regensburg, Germany \\ ${ }^{\mathrm{c}}$ Institute for Advanced Studies, Austria \\ ${ }^{\mathrm{d}}$ Department of Economics, University of California, Davis, CA 95616, United States
}

\section{A R T I C L E I N F O}

\section{Article history:}

Received 24 September 2012

Received in revised form

16 October 2013

Accepted 9 May 2014

Available online 2 June 2014

\section{JEL classification:}

E4

E5

E2

R2

R3

Keywords:

Agency costs

Credit channel

Time-varying uncertainty

Residential investment

Housing production

Calibration

\begin{abstract}
A B S T R A C T
This paper analyzes the role of stochastic uncertainty in a multi-sector housing model with financial frictions. We include time varying uncertainty (i.e. risk shocks) in the technology shocks that affect housing production and provide estimates of the time-series properties of risk shocks by using firm level productivity data. The analysis demonstrates that risk shocks to the housing production sector are a quantitatively important impulse mechanism for understanding housing price movements. Specifically, the model can match the volatility of housing prices observed in the data. It is also demonstrated that adjustment costs are important in replicating the contemporaneous correlation of housing prices with GDP and residential investment. Critically, bankruptcy costs act as an endogenous markup factor in housing prices and are an important determinant of house price volatility. However, in comparison to housing demand shocks, risk shocks have low explanatory power for real quantities.
\end{abstract}

(c) 2014 Elsevier B.V. All rights reserved.

\section{Introduction}

Given the recent macroeconomic experience of most developed countries, few economists would argue with the following three observations: (1) financial intermediation plays an important role in the economy; (2) the housing sector is a critical component for aggregate economic behavior; and (3) uncertainty, and, in particular, time-varying uncertainty is a quantitatively important source of business cycle activity. However, while an extensive research literature is associated with each of these ideas individually, there are none that we know of which studies their joint influences and interactions. ${ }^{2}$

\footnotetext{
* Corresponding author. Tel.: +1530554 1185 .

E-mail addresses: gabriel.lee@wiwi.uni-regensburg.de (G.S. Lee), kdsalyer@ucdavis.edu (K.D. Salyer).

1 Tel.: +499419435060.

2 Some of the recent works which also examine housing and credit are: Iacoviello and Minetti (2008) and Iacoviello and Neri (2010) in which a New-Keynesian DSGE two sector model is used in their empirical analysis; Iacoviello (2005) analyzes the role that real estate collateral has for monetary policy; and Aoki et al. (2004) analyze house price amplification effects in consumption and housing investment over the business cycle. More recently, Iacoviello (2013) includes a financial sector in a model with housing in order to study how loan default can effect the macroeconomy. None of these analyses use risk shocks as an impulse mechanism. Some recent papers that have examined the effects of uncertainty in a DSGE framework include Bloom
} 
The research presented here attempts to fill this void; in particular, we analyze the role of time varying uncertainty (i.e. risk shocks) in a multi-sector real business cycle model that includes housing production (developed by Davis and Heathcote, 2005) and a financial sector with lending under asymmetric information (e.g. Carlstrom and Fuerst, 1997, 1998; Dorofeenko et al., 2008). We model risk shocks as a mean preserving spread in the distribution of the technology shocks affecting house production and explore quantitatively howchanges in uncertainty affect equilibrium characteristics.

Our aim in examining this environment is twofold. First, we wish to develop a framework that can capture one of the main components of the recent financial crises, namely, changes in the risk associated with the housing sector. In our analysis, we focus entirely on the variations in risk associated with the production of housing and the consequences that this has for lending and economic activity. Hence our analysis is very much a fundamental-based approach so that we side-step the delicate issues of modeling housing bubbles and departures from rational expectations. The results, as discussed below, suggest (to us) that this conservative approach is warranted. ${ }^{3}$ Second, we want to cast the analysis of risk shocks in a model that is broadly consistent with some of the important stylized facts of the housing sector such as: (i) residential investment is about twice as volatile as non-residential investment and (ii) residential investment and non-residential investment are highly procyclical. ${ }^{4}$ Hence, we view our analysis as more of a quantitative rather than qualitative exercise.

With this in mind, we employ the Davis and Heathcote (2005) housing model which, when calibrated to the U.S. data, can replicate the high volatility observed in residential investment despite the absence of any frictions in the economy. The recent analysis in Christiano et al. (2013), however, provides compelling evidence that financial frictions do play an important role in business cycles and, given the recent financial events, it seems reasonable to investigate this role when combined with a housing sector. ${ }^{5}$ Consequently, we modify the Davis and Heathcote (2005) framework by adding a financial sector in the economy and require that housing producers must finance their inputs via loans from the banking sector. While this modification improves the model upon some dimensions, a notable discrepancy between model output and the data is the volatility of housing prices; this inconsistency was also prominent in the original Davis and Heathcote (2005) analysis. However, when risk shocks are added to the production of housing, the model produces greater house price volatility, but still less than that seen in the data. Also, the model with risk shocks generates excess volatility in several real variables such as residential investment. We find that adding adjustment costs to housing production with a quite reasonable value for the adjustment cost parameter eliminates this excess volatility in the real side and, importantly, the model now matches the observed volatility of housing prices. We demonstrate that housing prices in our model are affected by expected bankruptcies and the associated agency costs; these serve as an endogenous, time-varying markup factor affecting the price of housing. When risk shocks are added to the model, volatility in this markup translates into increased volatility in housing prices. Moreover, the model implies that this endogenous markup to housing as well as the risk premium associated with loans to the housing sector should be countercyclical; both of these features are seen in the data. ${ }^{6}$

It is important to point out that, since the quantitative results of the calibration exercise are emphasized here, the estimation of the time-series properties of the risk shocks plays an critical role in our calibration analysis. Previous literature (see Bloom et al., 2008; Gilchrist et al., 2008) have used financial data to empirically identify risk shocks but here we follow Chugh (2011) in using the cross-sectional variation in firm level productivity as our measure of time-varying uncertainty in housing production productivity.

As a final quantitative exercise, we introduce stochastic demand for housing in order to compare the magnitude of effects due to random housing demand vis-a-vis production uncertainty. (Our model of demand shocks follows that of Iacoviello and Neri, 2010.) Since demand shocks have a direct effect on the housing market, we show that these shocks dominate uncertainty shocks with respect to explaining the movements in the quantities, e.g residential investment. However, uncertainty shocks still play an important role in the lending market and are important for the model to capture housing price movements. Our results are consistent with the recent analysis of Bachmann et al. (2013) and Chugh (2011) which question the importance of risk shocks for the movement of real quantities; risk shocks, however, are critical for explaining price movements (here in the form of housing price volatility).

The next section lays out the model; this is followed by a section detailing how the parameter values were chosen. In the next section, equilibrium results are discussed. In that section, the quantitative role of uncertainty shocks, adjustment costs

\footnotetext{
(footnote continued)

et al. (2008), Fernández-Villaverde et al. (2011), Christiano et al. (2013), and Chugh (2011). The last paper is closely related to Dorofeenko et al. (2008) in that it demonstrates, using firm level data to estimate risk shocks, that in a standard financial accelerator model, the quantitative effects of risk shocks on aggregate quantities are modest.

3 In a closely related analysis, Kahn (2008) also uses a multi-sector framework in order to analyze time variation in the growth rate of productivity in a key sector (consumption goods). He demonstrates that a change in regime growth, combined with a learning mechanism, can account for some of the observed movements in housing prices.

${ }^{4}$ One other often mentioned stylized fact is that housing prices are persistent and mean reverting (e.g. Glaeser and Gyourko, 2006).

5 Christiano et al. (2013) use a New Keynesian model to analyze the relative importance of shocks arising in the labor and goods markets, monetary policy, and financial sector. They find that time-varying second moments, i.e. risk shocks, are quantitatively important relative to the other impulse mechanisms.

${ }^{6}$ In addition to these cyclical features, a marked feature of the housing sector has been the growth in residential and commercial real estate lending over the last decade. For example, residential real estate loans (excluding revolving home equity loans) account for approximately $50 \%$ of total lending by domestically chartered commercial banks in the United States over the period October 1996 to July 2007. Moreover, there is a strong co-movement between the amount of real estate loans and house prices.
} 
and housing demand shocks is presented. The paper concludes with some summarizing statements and suggestions for further research.

\section{Model description}

As stated above, our model builds on two separate strands of literature: Davis and Heathcote's (2005) multi-sector growth model with housing and Dorofeenko et al.'s (2008) credit channel model with time-varying uncertainty. For expositional clarity, we first briefly outline our variant of the multi-sector growth model with housing framework and then introduce the credit channel model.

\subsection{Production}

\subsubsection{Firms}

The economy consists of two agents, a consumer and an entrepreneur, and four sectors: an intermediate goods sector, a final goods sector, a housing goods sector and a banking sector. The intermediate sector is composed of three perfectly competitive industries: a building/construction sector, a manufacturing sector and a service sector. The output from these sectors is then combined to produce a residential investment good and a consumption good which can be consumed or used as capital investment; these sectors are also perfectly competitive. Entrepreneurs combine residential investment with a fixed factor (land) to produce housing; this sector is where the lending channel and financial intermediation play a role.

Turning first to the intermediate goods sector, the representative firm in each sector is characterized by the following Cobb-Douglas production function:

$$
x_{i t}=k_{i t}^{\theta_{i}}\left(n_{i t} \exp ^{z_{i t}}\right)^{1-\theta_{i}}
$$

where $i=b, m, s$ (building/construction, manufacture, service), $k_{i t}, n_{i t}$, and $z_{i t}$ are capital, household labor, and a labor augmenting productivity shock respectively for each sector, with $\theta_{i}$ being the share of capital for sector $i{ }^{7}$ In our calibration we set $\theta_{b}<\theta_{m}$ reflecting the fact that the manufacturing sector is more capital intensive (or less labor intensive) than the construction sector.

Productivity in each sector exhibits stochastic growth as given by

$$
z_{i t}=t \log \left(g_{z, i}\right)+\tilde{z}_{i t}
$$

where $g_{z, i}$ is the trend growth rate in sector $i$.

The vector of technology shocks, $\tilde{\mathbf{z}}=\left(\tilde{z}_{b}, \tilde{z}_{m}, \tilde{z}_{s}\right)$, follows an $A R(1)$ process:

$$
\tilde{\mathbf{z}}_{t+1}=B \cdot \tilde{\mathbf{z}}_{t}+\vec{\varepsilon}_{t+1}
$$

The innovation vector $\vec{\varepsilon}$ is distributed normally with a given covariance matrix $\Sigma_{\varepsilon} .8$

These intermediate firms maximize a conventional static profit function every period. That is, at time $t$, the objective function is

$$
\max _{\left\{k_{i t}, n_{i t}\right\}}\left\{\sum_{i} p_{i t} x_{i t}-r_{t} k_{i t}-w_{t} n_{i t}\right\}
$$

which results in the usual first order conditions for factor demand:

$$
r_{t} k_{i t}=\theta_{i} p_{i t} x_{i t}, \quad w_{t} n_{i t}=\left(1-\theta_{i}\right) p_{i t} x_{i t}
$$

where $r_{t}, w_{t}$, and $p_{i t}$ are the capital rental, wage, and output prices (with the consumption good as numeraire), respectively.

The intermediate goods are then used as inputs to produce two final goods, $y_{j}$, where $j=c, d$ (consumption/capital investment and residential investment respectively). This technology is also assumed to be Cobb-Douglas with constant returns to scale:

$$
y_{j t}=\prod_{i=b, m, s} x 1_{i j t}^{\rho_{i j}}, \quad j=c, d .
$$

Note that there are no aggregate technology shocks in the model. The input matrix is defined by

$$
\mathbf{x 1}=\left(\begin{array}{cc}
b_{c} & b_{d} \\
m_{c} & m_{d} \\
s_{c} & s_{d}
\end{array}\right),
$$

\footnotetext{
${ }^{7}$ Real estate developers, i.e. entrepreneurs, also provide labor to the intermediate goods sectors. This is a technical consideration so that the net worth of entrepreneurs, including those that go bankrupt, is positive. Labor's share for entrepreneurs is set to a trivial number and has no effect on output dynamics. Hence, for expositional purposes, we ignore this factor in the presentation.

${ }^{8}$ We abstract from a feature where a government sector is characterized by non-stochastic tax rates, government expenditures and a balanced budget in every period in order to focus on time varying uncertainty and the credit channel. Our original model included these elements but it was determined that they did not have much influence on the policy functions that characterize equilibrium (although they clearly influence steady-state values).
} 
where, for example, $m_{j}$ denotes the quantity of manufacturing output used as an input into sector $j$. The shares of construction, manufactures and services for sector $j$ are defined by the matrix

$$
\boldsymbol{\rho}=\left(\begin{array}{cc}
B_{c} & B_{d} \\
M_{c} & M_{d} \\
S_{c} & S_{d}
\end{array}\right)
$$

The relative shares of the three intermediate inputs differ in producing the two final goods. For example, in the calibration of the model, we set $B_{c}<B_{d}$ to represent the fact that residential investment is more construction input intensive relative to the consumption good sector. The first degree homogeneity of the production processes implies $\sum_{i} \rho_{i j}=1 ; j=c, d$ while market clearing in the intermediate goods markets requires $x_{i t}=\sum_{j} x 1_{i j t} ; i=b, m, s$.

With intermediate goods as inputs, the final goods' firms solve the following static profit maximization problem at $t$ (as stated earlier, the price of consumption good, $p_{c t}$, is normalized to (1)):

$$
\max _{x_{i j t}}\left\{y_{c t}+p_{d t} y_{d t}-\sum_{j} \sum_{i} p_{i t} x 1_{i j t}\right\}
$$

subject to the production functions (Eq. (6)) and non-negativity of inputs.

The first order conditions associated with profit maximization are given by the typical marginal conditions

$$
p_{i t} x 1_{i j t}=\rho_{i j} p_{j t} y_{j t} ; \quad i=b, m, s ; j=c, d
$$

Constant returns to scale implies zero profits in both sectors so we have the following relationships:

$$
\sum_{j} p_{j t} y_{j t}=\sum_{i} p_{i t} x_{i t}=r_{t} k_{t}+w_{t} n_{t}
$$

Finally, new housing structures, $y_{h t}$, are produced by entrepreneurs (i.e. real estate developers) using the residential investment good, $y_{d t}$, and land, $x_{l t}$, as inputs. This sector is discussed below following the description of the household and financial sectors.

\subsubsection{Households}

The representative household derives utility each period from consumption, $c_{t}$, housing, $h_{t}$, and leisure, $1-n_{t}$; all of these are measured in per-capita terms. Instantaneous utility for each member of the household is defined by the Cobb-Douglas functional form of ${ }^{9}$

$$
U\left(c_{t}, h_{t}, 1-n_{t}\right)=\frac{\left(c_{t}^{\mu_{c}} h_{t}^{\mu_{h}}\left(1-n_{t}\right)^{1-\mu_{c}-\mu_{h}}\right)^{1-\psi}}{1-\psi}
$$

where $\mu_{c}$ and $\mu_{h}$ are the weights for consumption and housing in utility, and $\sigma$ represents the coefficient of relative risk aversion. It is assumed that population grows at the (gross) rate of $\eta$ so that the household's objective function is written as

$$
E_{0} \sum_{t=0}^{\infty}(\beta \eta)^{t} U\left(c_{t}, h_{t}, 1-n_{t}\right)
$$

Each period agents combine labor income with income from capital and land and use these to purchase consumption, new housing and investment. In the purchase of housing (addition to the existing housing stock), agents interact with the financial intermediary which offers one unit of housing for the price of $p_{h t}$ units of consumption. As described below, the financial intermediary lends these resources to risky entrepreneurs who use them to buy the inputs into the housing production. For the household, these choices are represented by the per-capita budget constraint and the laws of motion for per-capita capital and housing:

$$
\begin{aligned}
& w_{t} n_{t}+r_{t} k_{t}+p_{l t} x_{l t}=c_{t}+i_{k t}+p_{h t} i_{h t} \\
& \eta k_{t+1}=k_{t}\left(1-\delta_{k}\right)+G\left(i_{k t}, i_{k t-1}\right) \\
& \eta h_{t+1}=h_{t}\left(1-\delta_{h}\right)+G\left(i_{h t}, i_{h t-1}\right)
\end{aligned}
$$

where $i_{k t}$ is capital investment, $i_{h t}$ is housing investment, $\delta_{k}$ and $\delta_{h}$ are the capital and house depreciation rates respectively. ${ }^{10}$ The function $G(\bullet)$ is used to introduce adjustment costs into both capital and housing accumulation.

\footnotetext{
${ }^{9}$ This functional form for preferences is the same as that in Davis and Heathcote (2005). In contrast, other DSGE analyses of housing have often employed separable preferences, e.g. Iacoviello (2005). We use the preferences (and technology, as described below) from Davis and Heathcote (2005) since their calibrated model matches many key features of the housing market as described in the Introduction. Also, we employ their methodology for calibrating many of the parameters of the model.

${ }^{10}$ Note that lower case variables for capital, labor and consumption represent per-capita quantities while upper case will denote aggregate quantities.
} 
For both stocks, we use the same functional form:

$$
G\left(i_{z t}, i_{z t-1}\right)=i_{z t}\left(1-S\left(\frac{i_{z t}}{i_{z t-1}}\right)\right)
$$

It is assumed that $S(1)=S^{\prime}(1)=0$ and $S^{\prime \prime}(1)=\kappa_{z}>0 ; z=(h, k)$; this is sufficient structure on the function given that we loglinearize the economy when solving for equilibrium. As shown by Christiano et al. (2005), the parameter $\kappa_{z}$ is the inverse of the elasticity of housing (capital) investment with respect to a temporary change in the shadow price of the housing (capital) stock, denoted $q_{h t}\left(q_{k t}\right)$. For more on the properties of this form of adjustment costs (which, importantly, affect the second derivative of the law of motion of capital rather than the usual first derivative), the reader is directed to Christiano et al. (2005).

It is also important to note that we follow Davis and Heathcote (2005) in that $h_{t}$ denotes effective housing units. Specifically, they exploit the geometric depreciation structure of housing structures in order to derive $h_{t}$. Furthermore, they derive the law of motion for effective housing units (in a model that does not include agency costs) and demonstrate that the depreciation rate $\delta_{h}$ is related to the depreciation rate of structures. As discussed in their analysis, it is not necessary to keep track of the stock of housing structures as an additional state variable; the amount of effective housing units, $h_{t}$, is a sufficient statistic.

The optimization problem leads to the following necessary conditions which represent, respectively, the Euler conditions associated with capital, housing, and the intra-temporal labor-leisure decision:

$$
\begin{aligned}
& U_{1 t}=U_{1 t} q_{k t} G_{1}\left(i_{k t}, i_{k t-1}\right)+\beta \eta E_{t}\left[U_{1 t+1} q_{k t+1} G_{2}\left(i_{k t+1}, i_{k t}\right)\right] \\
& U_{1 t} q_{k t}=\beta \eta E_{t}\left[U_{1 t+1}\left(r_{t+1}+q_{k t+1}(1-\delta)\right)\right] \\
& U_{1 t} p_{h t}=U_{1 t} q_{h t} G_{1}\left(i_{h t}, i_{h t-1}\right)+\beta \eta E_{t}\left[U_{1 t+1} q_{h t+1} G_{2}\left(i_{h t+1}, i_{h t}\right)\right] \\
& U_{1 t} q_{h t}=\beta \eta E_{t}\left[U_{1 t+1}\left(1-\delta_{h}\right) q_{h t+1}+U_{2 t+1}\right] \\
& w_{t}=\frac{U_{3}}{U_{1}} .
\end{aligned}
$$

As mentioned above, the terms $q_{k t}$ and $q_{h t}$ denote the shadow prices of capital and housing, respectively. Note that in the absence of adjustment costs (so that $G_{1}\left(i_{k t}, i_{k t-1}\right)=G_{1}\left(i_{h t}, i_{h t-1}\right)=1$ and $G_{2}\left(i_{k t+1}, i_{k t}\right)=G_{2}\left(i_{h t+1}\right.$, $\left.i_{h t}\right)=0$ ), these shadow prices are 1 and $p_{h t}$ as expected. These Euler equations have the standard marginal cost=marginal benefit interpretations. For instance, the left-hand side of Eq. (21) is the marginal cost of purchasing additional housing; at an optimum this must equal the expected marginal utility benefit of housing which comes from the capital value of undepreciated housing and the direct utility that additional housing provides. The shadow price, $q_{h t}$, used in this calculus is, in turn, related to the price of housing and the utility costs associated with housing adjustment costs as reflected in Eq. (20). The equations associated with capital have an analogous interpretation.

\subsection{The credit channel}

\subsubsection{Housing entrepreneurial contract}

The economy described above is identical to that studied in Davis and Heathcote (2005) except for the addition of productivity shocks affecting housing production. ${ }^{11}$ We describe in more detail the nature of this sector and the role of the banking sector. It is assumed that a continuum of housing producing firms with unit mass is owned by risk-neutral entrepreneurs (developers). The costs of producing housing are financed via loans from risk-neutral intermediaries. Given the realization of the idiosyncratic shock to housing production, some real estate developers will not be able to satisfy their loan payments and will go bankrupt. The banks take over operations of these bankrupt firms but must pay an agency fee. These agency fees, therefore, affect the aggregate production of housing and, as shown below, imply an endogenous markup to housing prices. That is, since some housing output is lost to agency costs, the price of housing must be increased in order to cover factor costs.

The timing of events is critical:

1. The exogenous state vector of technology shocks and uncertainty shocks, denoted $\left(z_{i, t}, \sigma_{\omega, t}\right)$, is realized.

2. Firms hire inputs of labor and capital from households and entrepreneurs and produce intermediate output via CobbDouglas production functions. These intermediate goods are then used to produce the two final outputs.

3. Households make their labor, consumption, housing, and investment decisions.

4. With the savings resources from households, the banking sector provides loans to entrepreneurs via the optimal financial contract (described below). The contract is defined by the size of the loan $\left(f p_{a t}\right)$ and a cutoff level of productivity for the entrepreneurs' technology shock, $\bar{\omega}_{t}$.

\footnotetext{
${ }^{11}$ Also, as noted above, we abstract from taxes and government expenditures.
} 


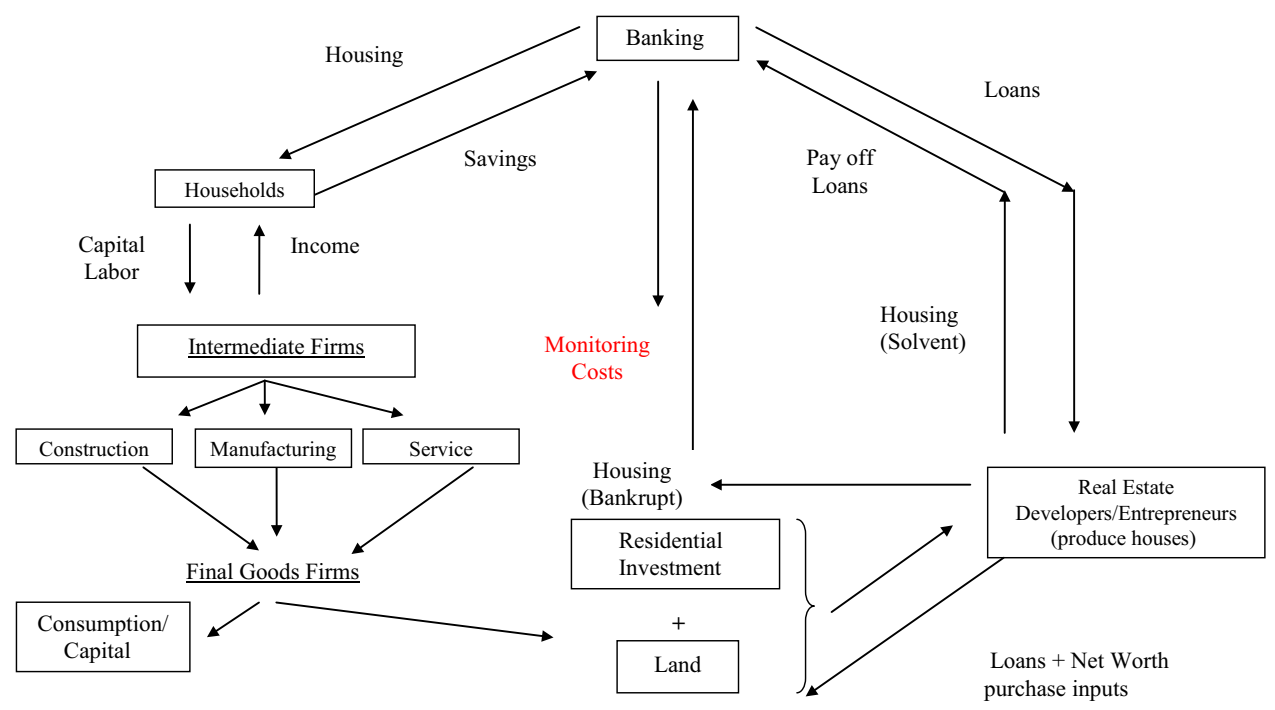

Fig. 1. Flow of funds in credit channel with housing model (households land income, as well as Entrepreneur labor input and income are not shown).

5. Entrepreneurs use their net worth and loans from the banking sector in order to purchase the factors for housing production. The quantity of factors (residential investment and land) is determined and paid for before the idiosyncratic technology shock is known.

6. The idiosyncratic technology shock of each entrepreneur is realized. If $\omega_{a t} \geq \bar{\omega}_{t}$ the entrepreneur is solvent and the loan from the bank is repaid; otherwise the entrepreneur declares bankruptcy and production is monitored by the bank at a cost proportional (but time varying) to total factor payments.

7. Solvent entrepreneur's sell their remaining housing output to the bank sector and use this income to purchase current consumption and capital. The latter will in part determine their net worth in the following period.

8. Note that the total amount of housing output available to the households is due to three sources: (1) the repayment of loans by solvent entrepreneurs, (2) the housing output net of agency costs by insolvent firms, and (3) the sale of housing output by solvent entrepreneurs used to finance the purchase of consumption and capital.

A schematic of the implied flows is presented in Fig. 1.

For entrepreneur $a$, the housing production function is denoted $F\left(x_{\text {alt }}, y_{\text {adt }}\right)$ and is assumed to exhibit constant returns to scale. Specifically, we assume

$$
y_{\text {aht }}=\omega_{a t} F\left(x_{\text {alt }}, y_{\text {adt }}\right)=\omega_{a t} x_{\text {alt }}^{1-\zeta} y_{\text {adt }}^{\zeta}
$$

where $(1-\zeta)$ denotes the share of land. It is assumed that the aggregate quantity of land is fixed and equal to 1 . The technology shock, $\omega_{a t}$, is an idiosyncratic shock affecting real estate developers. The technology shock is assumed to have a unitary mean. Its logarithm has standard deviation of $\sigma_{\omega, t}$. The standard deviation, $\sigma_{\omega, t}$, follows an $A R(1)$ process:

$$
\sigma_{\omega, t+1}=\sigma_{0}^{1-\chi} \sigma_{\omega, t}^{\chi} \exp ^{\varepsilon_{\sigma, t+1}}
$$

with the steady-state value $\sigma_{0}, \chi \in(0,1)$ and $\varepsilon_{\sigma, t+1}$ is a white noise innovation. ${ }^{12}$

Entrepreneurs enter each period with net worth given by $n w_{a t}$. Developers use this net worth and loans from the banking sector in order to purchase inputs. Letting $f p_{a t}$ denote the factor payments associated with developer $a$, we have

$$
f p_{a t}=p_{d t} y_{a d t}+p_{l t} x_{a l t}
$$

Hence, the size of the loan is $\left(f p_{a t}-n w_{a t}\right)$. The realization of $\omega_{a t}$ is privately observed by each entrepreneur; banks can observe the realization at a cost that is proportional to the total input bill.

It is convenient to express these agency costs in terms of the price of housing. Note that agency costs combined with constant returns to scale in housing production (see Eq. (23)) imply that the aggregate value of housing output must be greater than the value of inputs; i.e. housing must sell at a markup over the input costs, the factor payments. Denote this markup as $\bar{s}_{t}$ (which is treated as parametric by both lenders and borrowers) which satisfies

$$
p_{h t} y_{h t}=\bar{s}_{t} f p_{t}
$$

\footnotetext{
${ }^{12}$ This autoregressive process is used so that, when the model is log-linearized, $\hat{\sigma}_{\omega, t}$ (defined as the percentage deviations from $\sigma_{0}$ ) follows a standard, mean-zero AR(1) process.
} 
Also, since $E\left(\omega_{t}\right)=1$ and all firms face the same factor prices, this implies that, at the individual level, we have ${ }^{13}$

$$
p_{h t} F\left(x_{\text {alt }}, y_{\text {adt }}\right)=\bar{s}_{t} f p_{a t}
$$

Given these relationships, we define agency costs for loans to an individual entrepreneur in terms of foregone housing production as $\mu \bar{s}_{t} f p_{a t}$.

With a positive net worth, the entrepreneur borrows $\left(f p_{a t}-n w_{a t}\right)$ consumption goods and agrees to pay back $\left(1+r_{t}^{L}\right)\left(f p_{a t}-n w_{a t}\right)$ to the lender, where $r_{t}^{L}$ is the interest rate on loans. The cutoff value of productivity, $\bar{\omega}_{t}$, that determines solvency (i.e. $\omega_{a t} \geq \bar{\omega}_{t}$ ) or bankruptcy (i.e. $\omega_{a t}<\bar{\omega}_{t}$ ) is defined by

$$
\left(1+r_{t}^{L}\right)\left(f p_{a t}-n w_{a t}\right)=p_{h t} \bar{\omega}_{t} F\left(x_{a l t}, y_{a d t}\right)
$$

Denoting the c.d.f. and p.d.f. of $\omega_{t}$ as $\Phi\left(\omega_{t} ; \sigma_{\omega, t}\right)$ and $\phi\left(\omega_{t} ; \sigma_{\omega, t}\right)$, the expected returns to a housing producer are therefore given by $^{14}$

$$
\int_{\bar{\omega}_{t}}^{\infty}\left[p_{h t} \omega F(\cdot)-\left(1+r_{t}^{L}\right)\left(f p_{a t}-n w_{a t}\right)\right] \phi\left(\omega ; \sigma_{\omega, t}\right) d \omega
$$

Using the definition of $\bar{\omega}_{t}$ and Eq. (27), this can be written as

$$
\bar{s}_{t} f p_{a t} f\left(\bar{\omega}_{t} ; \sigma_{\omega, t}\right)
$$

where $f\left(\bar{\omega}_{t} ; \sigma_{\omega, t}\right)$ is defined as

$$
f\left(\bar{\omega}_{t} ; \sigma_{\omega, t}\right)=\int_{\bar{\omega}_{t}}^{\infty} \omega \phi\left(\omega ; \sigma_{\omega, t}\right) d \omega-\left[1-\Phi\left(\bar{\omega}_{t} ; \sigma_{\omega, t}\right)\right] \bar{\omega}_{t}
$$

Similarly, the expected returns to lenders are given by

$$
\int_{0}^{\bar{\omega}_{t}} p_{h t} \omega F(\cdot) \phi\left(\omega ; \sigma_{\omega, t}\right) d \omega+\left[1-\Phi\left(\bar{\omega}_{t} ; \sigma_{\omega, t}\right)\right]\left(1+r_{t}^{L}\right)\left(f p_{a t}-n w_{a t}\right)-\Phi\left(\bar{\omega}_{t} ; \sigma_{\omega, t}\right) \mu \bar{s}_{t} f p_{a t}
$$

Again, using the definition of $\bar{\omega}_{t}$ and Eq. (27), this can be expressed as

$$
\bar{s}_{t} f p_{a t} g\left(\bar{\omega}_{t} ; \sigma_{\omega, t}\right)
$$

where $g\left(\bar{\omega}_{t} ; \sigma_{\omega, t}\right)$ is defined as

$$
g\left(\bar{\omega}_{t} ; \sigma_{\omega, t}\right)=\int_{0}^{\bar{\omega}_{t}} \omega \phi\left(\omega ; \sigma_{\omega, t}\right) d \omega+\left[1-\Phi\left(\bar{\omega}_{t} ; \sigma_{\omega, t}\right)\right] \bar{\omega}_{t}-\Phi\left(\bar{\omega}_{t} ; \sigma_{\omega, t}\right) \mu
$$

Note that these two functions sum to

$$
f\left(\bar{\omega}_{t} ; \sigma_{\omega, t}\right)+g\left(\bar{\omega}_{t} ; \sigma_{\omega, t}\right)=1-\Phi\left(\bar{\omega}_{t} ; \sigma_{\omega, t}\right) \mu
$$

Hence, the term $\Phi\left(\bar{\omega}_{t} ; \sigma_{\omega, t}\right) \mu$ captures the loss of housing due to the agency costs associated with bankruptcy. With the expected returns to lender and borrower expressed in terms of the size of the loan, $f p_{a t}$, and the cutoff value of productivity, $\bar{\omega}_{t}$, it is possible to define the optimal borrowing contract by the pair $\left(f p_{a t}, \bar{\omega}_{t}\right)$ that maximizes the entrepreneur's return subject to the lender's willingness to participate (all rents go to the entrepreneur). That is, the optimal contract is determined by the solution to

$$
\max _{\bar{\omega}_{t}, f p_{a t}} \bar{s}_{t} f p_{a t} f\left(\bar{\omega}_{t} ; \sigma_{\omega, t}\right) \text { subject to } \bar{s}_{t} f p_{a t} g\left(\bar{\omega}_{t} ; \sigma_{\omega, t}\right) \geq f p_{a t}-n w_{a t}
$$

A necessary condition for the optimal contract problem is given by

$$
\frac{\partial(\cdot)}{\partial \bar{\omega}_{t}}: \bar{s}_{t} f p_{a t} \frac{\partial f\left(\bar{\omega}_{t} ; \sigma_{\omega, t}\right)}{\partial \bar{\omega}_{t}}=-\lambda_{t} \bar{s}_{t} f p_{a t} \frac{\partial g\left(\bar{\omega}_{t} ; \sigma_{\omega, t}\right)}{\partial \bar{\omega}_{t}}
$$

where $\lambda_{t}$ is the shadow price of the lender's resources. Using the definitions of $f\left(\bar{\omega}_{t} ; \sigma_{\omega, t}\right)$ and $g\left(\bar{\omega}_{t} ; \sigma_{\omega, t}\right)$, this can be rewritten as $^{15}$

$$
1-\frac{1}{\lambda_{t}}=\frac{\phi\left(\bar{\omega}_{t} ; \sigma_{\omega, t}\right)}{1-\Phi\left(\bar{\omega}_{t} ; \sigma_{\omega, t}\right)} \mu
$$

As shown by Eq. (38), the shadow price of the resources used in lending is an increasing function of the relevant Inverse Mill's ratio (interpreted as the conditional probability of bankruptcy) and the agency costs. If the product of these terms equals zero, then the shadow price equals the cost of housing production, i.e. $\lambda_{t}=1$.

\footnotetext{
${ }^{13}$ The implication is that, at the individual level, the product of the markup $\left(\bar{S}_{t}\right)$ and factor payments is equal to the expected value of housing production since housing output is unknown at the time of the contract. Since there is no aggregate risk in housing production, we also have $p_{h t} y_{h t}=\bar{s}_{t} f p_{t}$.

${ }^{14}$ The notation $\Phi\left(\omega ; \sigma_{\omega, t}\right)$ is used to denote that the distribution function is time-varying as determined by the realization of the random variable, $\sigma_{\omega, t}$.

15 Note that we have used the fact that $\partial f\left(\bar{\omega}_{t} ; \sigma_{\omega, t}\right) / \partial \bar{\omega}_{t}=\Phi\left(\bar{\omega}_{t} ; \sigma_{\omega, t}\right)-1<0$.
} 
The second necessary condition is

$$
\frac{\partial(\cdot)}{\partial f p_{a t}}: \bar{s}_{t} f\left(\bar{\omega}_{t} ; \sigma_{\omega, t}\right)=\lambda_{t}\left[1-\bar{s}_{t} g\left(\bar{\omega}_{t} ; \sigma_{\omega, t}\right)\right]
$$

These first-order conditions imply that, in general equilibrium, the markup factor, $\bar{s}_{t}$, will be endogenously determined and related to the probability of bankruptcy. Specifically, using the first order conditions, we have that the markup, $\bar{s}_{t}$, must satisfy

$$
\bar{s}_{t}^{-1}=\left[\left(f\left(\bar{\omega}_{t} ; \sigma_{\omega, t}\right)+g\left(\bar{\omega}_{t} ; \sigma_{\omega, t}\right)\right)+\frac{\phi\left(\bar{\omega}_{t} ; \sigma_{\omega, t}\right) \mu f\left(\bar{\omega}_{t} ; \sigma_{\omega, t}\right)}{\frac{\partial f\left(\bar{\omega}_{t} ; \sigma_{\omega, t}\right)}{\partial \bar{\omega}_{t}}}\right]=[1-\underbrace{\Phi\left(\bar{\omega}_{t} ; \sigma_{\omega, t}\right) \mu}_{A}-\underbrace{\frac{\phi\left(\bar{\omega}_{t} ; \sigma_{\omega, t}\right)}{1-\Phi\left(\bar{\omega}_{t} ; \sigma_{\omega, t}\right)} \mu f\left(\bar{\omega}_{t} ; \sigma_{\omega, t}\right)}_{B}]
$$

First note that the markup factor depends only on economy-wide variables so that the aggregate markup factor is well defined. Also, the two terms, $A$ and $B$, demonstrate that the markup factor is affected by both the total agency costs (term $A$ ) and the marginal effect that bankruptcy has on the entrepreneur's expected return. That is, term $B$ reflects the loss of housing output, $\mu$, weighted by the expected share that would go to entrepreneur's, $f\left(\bar{\omega}_{t} ; \sigma_{\omega, t}\right)$, and the conditional probability of bankruptcy (the Inverse Mill's ratio). Finally, note that, in the absence of credit market frictions, there is no markup so that $\bar{s}_{t}=1$. In the partial equilibrium setting, it is straightforward to show that Eq. (40) defines an implicit function $\bar{\omega}\left(\bar{s}_{t}, \sigma_{\omega, t}\right)$ that is increasing in $\bar{s}_{t}$.

The incentive compatibility constraint implies

$$
f p_{a t}=\frac{1}{\left(1-\bar{s}_{t} g\left(\bar{\omega}_{t} ; \sigma_{\omega, t}\right)\right)} n w_{a t}
$$

Eq. (41) implies that the size of the loan is linear in entrepreneur's net worth so that aggregate lending is well-defined and a function of aggregate net worth.

The effect of an increase in uncertainty on lending can be understood in a partial equilibrium setting where $\bar{s}_{t}$ and $n w_{a t}$ are treated as parameters. As shown by Eq. (40), the assumption that the markup factor is unchanged implies that the costs of default, represented by the terms $A$ and $B$, must be constant. With a mean-preserving spread in the distribution for $\omega_{t}$, this means that $\bar{\omega}_{t}$ will fall (this is driven primarily by the term $A$ ). Through an approximation analysis, it can be shown that $\bar{\omega}_{t} \approx g\left(\bar{\omega}_{t} ; \sigma_{\omega, t}\right)$ (see the Appendix in Dorofeenko et al., 2008). That is, the increase in uncertainty will reduce lenders' expected return $\left(g\left(\bar{\omega}_{t} ; \sigma_{\omega, t}\right)\right)$. Rewriting the binding incentive compatibility constraint (Eq. (41)) yields

$$
\bar{s}_{t} g\left(\bar{\omega}_{t} ; \sigma_{\omega, t}\right)=1-\frac{n w_{a t}}{f p_{a t}}
$$

the fall in the left-hand side induces a fall in $f p_{a t}$. Hence, greater uncertainty results in a fall in housing production. This partial equilibrium result carries over to the general equilibrium setting.

The existence of the markup factor implies that inputs will be paid less than their marginal products. In particular, profit maximization in the housing development sector implies the following necessary conditions:

$$
\begin{aligned}
& \frac{p_{l t}}{p_{h t}}=\frac{F_{x_{l}}\left(x_{l t}, y_{d t}\right)}{\bar{s}_{t}} \\
& \frac{p_{d t}}{p_{h t}}=\frac{F_{y_{d}}\left(x_{l t}, y_{d t}\right)}{\bar{s}_{t}}
\end{aligned}
$$

These expressions demonstrate that, in equilibrium, the endogenous markup (determined by the agency costs) will be a determinant of housing prices.

The production of new housing is determined by a Cobb-Douglas production with residential investment and land (fixed in equilibrium) as inputs. Denoting housing output, net of agency costs, as $y_{h t}$, this is given by

$$
y_{h t}=x_{l t}^{1-\zeta} y_{d t}^{\zeta}
$$

In equilibrium, we require that $i_{h t}=y_{h t}\left[1-\Phi\left(\bar{\omega}_{t} ; \sigma_{\omega, t}\right) \mu\right]$; i.e. household's housing investment is equal to housing output less monitoring cost. Recall that the law of motion for housing is given by Eq. (16).

\subsubsection{Entrepreneurial consumption and house prices}

To rule out self-financing by the entrepreneur (i.e. which would eliminate the presence of agency costs), it is assumed that the entrepreneur discounts the future at a faster rate than the household. This is represented by the following expected utility function:

$$
E_{0} \sum_{t=0}^{\infty}(\beta \eta \gamma)^{t} c_{t}^{e}
$$

where $c_{t}^{e}$ denotes entrepreneur's per-capita consumption at date $t$, and $\gamma \in(0,1)$. This new parameter, $\gamma$, will be chosen so that it offsets the steady-state internal rate of return due to housing production. 
Each period, entrepreneur's net worth, $n w_{t}$ is determined by the value of capital income and the remaining capital stock. ${ }^{16}$ That is, entrepreneurs use capital to transfer wealth over time (recall that the housing stock is owned by households). Denoting entrepreneur's capital as $k_{t}^{e}$, this implies ${ }^{17}$

$$
n w_{t}=k_{t}^{e}\left[r_{t}+1-\delta_{\kappa}\right]
$$

The law of motion for entrepreneurial capital stock is determined in two steps. First, new capital is financed by the entrepreneurs' value of housing output after subtracting consumption:

$$
\eta k_{t+1}^{e}=p_{h t} y_{a h t} f\left(\bar{\omega}_{t} ; \sigma_{\omega, t}\right)-c_{t}^{e}=\bar{s}_{t} f p_{a t} f\left(\bar{\omega}_{t} ; \sigma_{\omega, t}\right)-c_{t}^{e}
$$

Note we have used the equilibrium condition that $p_{h t} y_{a h t}=\bar{s}_{t} f p_{a t}$ to introduce the markup, $\bar{s}_{t}$, into the expression. Then, using the incentive compatibility constraint, Eq. (41), and the definition of net worth, the law of motion for capital is given by

$$
\eta k_{t+1}^{e}=k_{t}^{e}\left(r_{t}+1-\delta_{\kappa}\right) \frac{\bar{s}_{t} f\left(\bar{\omega}_{t} ; \sigma_{\omega, t}\right)}{1-\bar{s}_{t} g\left(\bar{\omega}_{t} ; \sigma_{\omega, t}\right)}-c_{t}^{e}
$$

The term $\bar{s}_{t} f\left(\bar{\omega}_{t} ; \sigma_{\omega, t}\right) /\left(1-\bar{s}_{t} g\left(\bar{\omega}_{t} ; \sigma_{\omega, t}\right)\right)$ represents the entrepreneur's internal rate of return due to housing production; alternatively, it reflects the leverage enjoyed by the entrepreneur since

$$
\frac{\bar{s}_{t} f\left(\bar{\omega}_{t} ; \sigma_{\omega, t}\right)}{1-\bar{s}_{t} g\left(\bar{\omega}_{t} ; \sigma_{\omega, t}\right)}=\frac{\bar{s}_{t} f p_{a t} f\left(\bar{\omega}_{t} ; \sigma_{\omega, t}\right)}{n w_{t}}
$$

That is, entrepreneurs use their net worth to finance factor inputs of value $f p_{a t}$, this produces housing which sells at the markup $\bar{s}_{t}$ with entrepreneur's retaining fraction $f\left(\bar{\omega}_{t} ; \sigma_{\omega, t}\right)$ of the value of housing output.

Given this setting, the optimal path of entrepreneurial consumption implies the following Euler equation:

$$
1=\beta \eta \gamma E_{t}\left[\left(r_{t+1}+1-\delta_{\kappa}\right) \frac{\bar{s}_{t+1} f\left(\bar{\omega}_{t+1} ; \sigma_{\omega, t+1}\right)}{1-\bar{s}_{t+1} g\left(\bar{\omega}_{t+1} ; \sigma_{\omega, t+1}\right)}\right]
$$

Finally, we can derive an explicit relationship between entrepreneur's capital and the value of the housing stock using the incentive compatibility constraint and the fact that housing sells at a markup over the value of factor inputs. Since $p_{h t} F\left(x_{a l t}, y_{a d t}\right)=\bar{s}_{t} f p_{t}$, the incentive compatibility constraint implies

$$
p_{h t}\left(x_{l t}^{1-\zeta} y_{d t}^{\zeta}\right)=k_{t}^{e} \frac{\left(r_{t}+1-\delta_{\kappa}\right)}{1-\bar{s}_{t} g\left(\bar{\omega}_{t} ; \sigma_{\omega, t}\right)} \bar{s}_{t}
$$

Again, it is important to note that the markup parameter plays a key role in determining housing prices and output.

\subsubsection{Financial intermediaries}

The banks in the model act as risk-neutral financial intermediaries that, in equilibrium, earn zero profits. There is a clear role for banks in this economy since, through pooling, all aggregate uncertainty of housing production can be eliminated. The banking sector receives deposits from households and, in return, agents receive a housing for a certain (i.e. risk-free) price. Hence, in this model, financial intermediaries act more like an aggregate housing cooperative rather than a typical bank.

\section{Equilibrium}

Prior to solving for equilibrium, it is necessary to express the growing economy in stationary form. Given that preferences and technologies are Cobb-Douglas, the economy will have a balanced growth path. Hence, it is possible to transform all variables by the appropriate growth factor. The output value of all markets (e.g. $p_{d} y_{d}, y_{c}, p_{i} x_{i}$ for $\left.i=(b, m, s)\right)$ is growing at the same rate as capital and consumption, $g_{k}$. This growth rate, in turn, is a geometric average of the growth rates in the intermediate sectors: $g_{k}=g_{z b}^{B_{c}} g_{z m}^{M_{c}} g_{z s}^{S_{c}}$. It is also the case that factor prices display the normal behavior along a balanced growth path: interest rates are stationary while the wage in all sectors is growing at the same rate. The growth rates for the various factors are presented in Table 1 (see Davis and Heathcote, 2005 for details). These growth factors were used to construct a stationary economy; all subsequent discussion is in terms of this transformed economy.

Equilibrium in the economy is described by the vector of factor prices $\left(w_{t}, r_{t}\right)$, the vector of intermediate goods prices $\left(p_{b t}, p_{m t}, p_{s t}\right)$, the price of residential investment $\left(p_{d t}\right)$, the price of land $\left(p_{l t}\right)$, the price of housing $\left(p_{h t}\right)$, the shadow prices associated with housing and capital (due to adjustment costs) $\left(q_{h t}, q_{k t}\right)$, and the markup factor $\left(\bar{s}_{t}\right)$. In total, therefore, there are 11 equilibrium prices. In addition, the following quantities are determined in equilibrium: the vector of intermediate goods $\left(x_{m t}, x_{b t}, x_{s t}\right)$, the vector of labor inputs $\left(n_{m t}, n_{b t}, n_{s t}\right)$, the total amount of labor supplied ( $\left.n_{t}\right)$, the vector of inputs into the final goods sectors $\left(b_{c t}, b_{d t}, m_{c t}, m_{d t}, s_{c t}, s_{d t}\right)$, the vector of capital inputs $\left(k_{m t}, k_{b t}, k_{s t}\right)$, entrepreneurial capital $\left(k_{t}^{e}\right)$, household investment $\left(k_{t+1}\right)$, the vector of final goods output $\left(y_{c t}, y_{d t}\right)$, the technology cutoff level $\left(\bar{\omega}_{t}\right)$, the effective housing stock $\left(h_{t+1}\right)$, and the consumption of households and entrepreneurs $\left(c_{t}, c_{t}^{e}\right)$. In total, there are 24 quantities to be

\footnotetext{
${ }^{16}$ As stated in footnote 7, net worth is also a function of current labor income so that net worth is bounded above zero in the case of bankruptcy. However, since entrepreneur's labor share is set to a very small number, we ignore this component of net worth in the exposition of the model.

${ }^{17}$ For expositional purposes, in this section we drop the subscript $a$ denoting the individual entrepreneur.
} 
Table 1

Growth rates on the balanced growth path.

\begin{tabular}{ll}
\hline$n_{b}, n_{m}, n_{s}, n, r$ & 1 \\
$k_{b}, k_{m}, k_{s}, k, c, y_{c}, w$ & $g_{k}=\left[g_{z b}^{B_{c}\left(1-\theta_{b}\right)} g_{z m}^{M_{c}\left(1-\theta_{m}\right)} g_{z s}^{S_{c}\left(1-\theta_{s}\right)}\right]^{\left(1 /\left(1-B_{c} \theta_{b}-M_{c} \theta_{m}-S_{c} \theta_{s}\right)\right)}$ \\
$b_{c}, b_{d}, x_{b}$ & $g_{b}=g_{k}^{\theta_{b}} g_{z b}^{1-\theta_{b}}$ \\
$m_{c}, m_{d}, x_{m}$ & $g_{m}=g_{k}^{\theta_{m}} g_{z m}^{1-\theta_{m}}$ \\
$s_{c}, s_{d}, x_{s}$ & $g_{s}=g_{k}^{\theta_{s}} g_{z s}^{1-\theta_{s}}$ \\
$y_{d}$ & $g_{d}=g_{b}^{B_{h}} g_{m}^{M_{h}} g_{s}^{S_{h}}$ \\
$x_{l}$ & $g_{l}=\eta^{-1}$ \\
$y_{h}, h$ & $g_{h}=g_{l}^{1-\zeta} g_{d}^{\zeta}$ \\
$p_{h} y_{h}, p_{d} x_{d}, p_{l} x_{l}, p_{b} x_{b}, p_{m} x_{m}, p_{s} x_{s}$ & $g_{k}$ \\
\hline
\end{tabular}

Table 2

Key preference and production parameters.

\begin{tabular}{ll}
\hline Depreciation rate for capital: $\delta_{\kappa}$ & 0.056 \\
Depreciation rate for effective housing $(h): \delta_{h}$ & 0.014 \\
Land's share in new housing: $(1-\zeta)$ & 0.106 \\
Population growth rate: $\eta$ & 1.017 \\
Discount factor: $\beta$ & 0.951 \\
Risk aversion: $\psi$ & 2.00 \\
Consumption's share in utility: $\mu_{c}$ & 0.314 \\
Housing's share in utility: $\mu_{h}$ & 0.044 \\
Leisure's share in utility: $1-\mu_{c}-\mu_{h}$ & 0.642 \\
\hline
\end{tabular}

determined; adding the 11 prices, the system is defined by 35 unknowns. The equations defining the equilibrium policy functions are presented in the Appendix. We solve for these by log-linearizing around the steady-state and computing the linear policy functions that are the solution to the resulting system of linear expectational difference equations.

\section{Calibration and data}

Table 2 presents parameter values for preferences, depreciation rates, population growth and land's share. Moreover, we use the same technology parameters describing the final goods sector (i.e. the vectors $\left(B_{c}, M_{c}, S_{c}\right)$ and $\left.\left(B_{d}, M_{d}, S_{d}\right)\right)$ as estimated by Davis and Heathcote (2005). We do, however, update their estimates of the intermediate goods technology parameters as described by the vector $\left(\theta_{b}, \theta_{m}, \theta_{s}\right)$ using more recent data as described in the Appendix. These parameter values are given in Table 3 .

The exogenous shocks to productivity in the three sectors are assumed to follow an autoregressive process as given in Eq. (3). The parameters for the vector autoregression are estimated using the detrended Solow residuals for each sector. Again, the data used and estimation methods are described in the Appendix. This resulted in the following values (recall that the rows of the $B$ matrix correspond to the building, manufacturing, and services sectors, respectively):

$$
B=\left(\begin{array}{ccc}
0.747 & -0.129 & -0.392 \\
0.255 & 0.450 & 0.151 \\
0.100 & 0.102 & 0.208
\end{array}\right)
$$

Note this implies that productivity shocks have modest dynamic effects across sectors. The contemporaneous correlations of the innovations to the shock are given by the correlation matrix:

$$
\Sigma=\left(\begin{array}{ccc}
\operatorname{Corr}\left(\varepsilon_{b}, \varepsilon_{b}\right) & \operatorname{Corr}\left(\varepsilon_{b}, \varepsilon_{m}\right) & \operatorname{Corr}\left(\varepsilon_{b}, \varepsilon_{s}\right) \\
& \operatorname{Corr}\left(\varepsilon_{m}, \varepsilon_{m}\right) & \operatorname{Corr}\left(\varepsilon_{m}, \varepsilon_{s}\right) \\
& & \operatorname{Corr}\left(\varepsilon_{s}, \varepsilon_{s}\right)
\end{array}\right)=\left(\begin{array}{ccc}
1 & 0.051 & 0.202 \\
& 1 & 0.382 \\
& & 1
\end{array}\right)
$$

The standard deviations for the innovations were estimated to be $\left(\sigma_{b b}, \sigma_{m m}, \sigma_{s s}\right)=(0.025,0.032,0.014)$.

We now turn to the calibration of the additional impulse mechanism of uncertainty or risk shocks. To estimate the time series properties of the risk shocks, we employ an empirical strategy in which the cross-sectional variation in firm level technology shocks (i.e. the Solow residual) is used as a proxy for the uncertainty shock. ${ }^{18}$ In particular, we use Compustat Industry Specific quarterly data over the sample period 2001-2011 and estimate the firm-level Solow residual associated with housing production (see Eq. (23)) using two intersecting subsets of firms: (i) firms with S\&P GIC sub-industry code

\footnotetext{
${ }^{18}$ Our approach is similar to that in Chugh (2011).
} 
Table 3

Intermediate production technology parameters.

\begin{tabular}{lccc}
\hline Parameter & $B$ & S \\
\hline Input shares for consumption/investment good $\left(B_{c}, M_{c}, S_{c}\right)$ & 0.031 & 0.270 \\
Input shares for residential investment $\left(B_{d}, M_{d}, S_{d}\right)$ & 0.470 & 0.700 \\
Capital's share in each sector $\left(\theta_{b}, \theta_{m}, \theta_{s}\right)$ & 0.106 & 0.292 & 0.330 \\
Sectoral trend productivity growth $(\%)\left(g_{z b}, g_{z m}, g_{z s}\right)$ & -0.27 & 2.85 & 1.65 \\
\hline
\end{tabular}

25201030 - Homebuilding (47 firms) and (ii) firms with NAICS sub-industry code 23611 (sub-industries 236115-236118) Residential Building Construction (35 firms). Hence, we first estimate the following regression:

$$
\log \left(\frac{y_{\text {hat }}}{x_{\text {alt }}}\right)=c+\zeta \log \left(\frac{y_{\text {adt }}}{x_{\text {alt }}}\right)+\log \omega_{a t}
$$

where $a$ and $t$ denote firm and time respectively. In the data, $y_{\text {hat }}$ is measured as the dollar value of housing units subject to pending sales contracts (i.e. defined as "backlogs" in the data set), $x_{\text {alt }}$ is measured as the dollar value of land under development, and $y_{a d t}$ is the difference between the nominal value of total homebuilding inventories and undeveloped inventories owned. ${ }^{19}$

The estimated firm level residuals are used to construct a measure of the aggregate shock at time $t$ :

$$
\Omega_{t} \equiv \frac{1}{N_{t}} \sum_{a=1}^{N_{t}} \omega_{a t}
$$

where $N_{t}$ is the number of firms at time $t$. Then the idiosyncratic shocks are normalized relative to this mean ${ }^{20}$ :

$$
\tilde{\omega}_{a t}=\frac{\omega_{a t}}{\Omega_{t}}
$$

Finally, the cross-sectional variation in this normalized productivity shock is used to measure the risk shock at time $t$ :

$$
\sigma_{t}=\sqrt{\frac{1}{N_{t}} \sum_{a=1}^{N_{t}}\left(\tilde{\omega}_{a t}-1\right)^{2}} .
$$

This series is detrended using the HP filter and the detrended series is used to construct the parameter estimates of $\left(\sigma_{\sigma}, \chi\right)$ used in the numerical analysis. ${ }^{21}$ That is, we estimate

$$
\log \left(\sigma_{t}\right)=\chi \log \left(\sigma_{t-1}\right)+\varepsilon_{t}
$$

where $\varepsilon_{t} \sim N\left(0, \sigma_{\sigma}^{2}\right)$. This procedure produced the estimate of the unconditional mean of uncertainty as $\sigma_{\sigma}=0.15$ with persistence parameter $\chi=0.005^{22}$

The time-series for the constructed aggregate productivity shock and the risk shocks from both subsets of firms are shown in Fig. 2. First note that, comfortingly, both datasets produce similar time series for the two series. While the negative correlation of the trends for each series is interesting and worth further study, here we focus on the business cycle characteristics. As expected, the recent recession (the shaded portion of the graphs) corresponds to a fall in productivity (i.e. productivity is procyclical) while risk is countercyclical. While the short sample period combined with the fact that the trend estimation is influenced by the end-of-sample data points implies that caution needs to be taken in assessing the accuracy of these cyclical features, they do correspond to the estimates provided by others (for example, see Bloom et al., 2008).

In order to calibrate the average (i.e. steady-state) standard deviation of the technology shocks, i.e. $\sigma_{0}$, and the steadystate cutoff productivity level of $\bar{\omega}_{t}$, denoted $\varpi$, we follow Carlstrom and Fuerst (1997) and use their values for the average bankruptcy rate in the data as well as the average risk premium on bank loans. Expressed as an annual yield, the average bankruptcy rate used by Carlstrom and Fuerst (1997) was 3.9\% implying $\Phi\left(\varpi, \sigma_{0}\right)=3.90$ while the average spread between the prime rate and the 3 -month commercial paper rate was $1.9 \%$.

\footnotetext{
${ }^{19}$ Note that while we use nominal values in the estimation, the assumptions of competitive factor and output markets and Cobb-Douglas technology implies that the estimated profit shocks are proportional to the underlying productivity shocks.

${ }^{20}$ Recall that the aggregate shock to the housing production sector is assumed to be unity. The definition of the idiosyncratic shock imposes this restriction.

${ }^{21}$ Note that we pass the aggregate measure of the risk shock through the HP filter rather than first detrending the individual series, $\tilde{\omega}_{a t}$. We do this for two reasons: (1) Since our interest is on aggregate behavior, we think it reasonable to apply one filter to the aggregate (measured as cross-sectional variation in productivity) measure of risk shocks $\left(\sigma_{t}\right)$ rather than the firm level Solow residual, $\omega_{a t}$. (2) On an operational level, there are many missing observation in the panel data for the series $\left(y_{\text {hat }}, y_{a d t}, x_{a l t}\right)$. Using the cross-sectional aggregate measure of $\sigma_{t}$ eliminates this problem.

22 Since the estimates for $\omega_{a t}$ were produced using quarterly data while the periodicity of the model (and other data values) is assumed to be annual, the quarterly estimates of $\left(\sigma_{\sigma}, \chi\right)$ were adjusted to an annual frequency.
} 

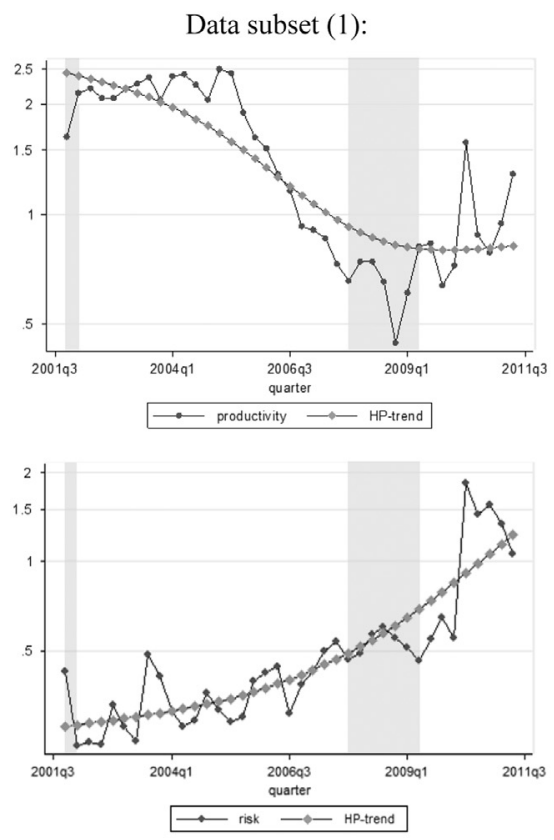

Data subset (2):
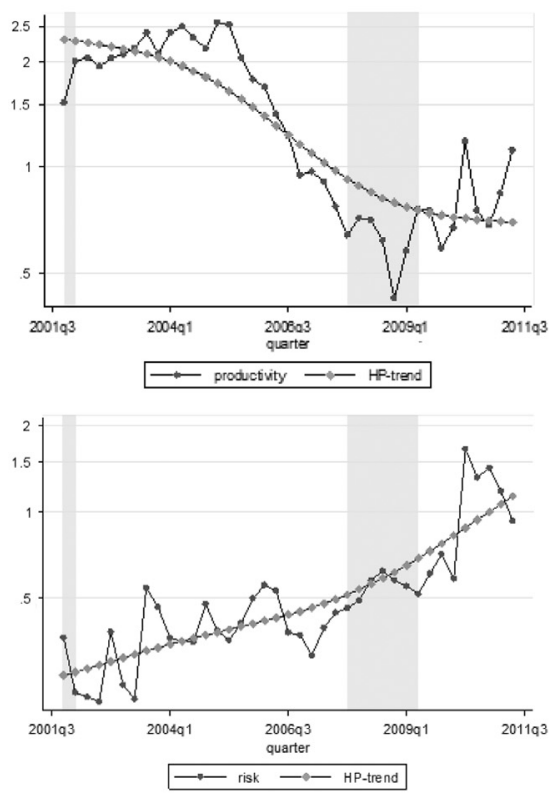

Fig. 2. Estimated productivity $\left(\Omega_{t}\right)$ and idiosyncratic risk $\left(\sigma_{t}\right)$ with H-P trends. Data subset (1) and Data subset (2).

Hence, from the model we choose $\left(\varpi, \sigma_{0}\right)$ so that the following two expressions hold (for the restriction Eq. (54), see Eqs. (28), (27), and (41)):

$$
\begin{aligned}
& \Phi\left(\varpi, \sigma_{0}\right)=3.90 \\
& \left(1+r_{t}^{L}\right)=\frac{p_{h t} \bar{\omega}_{t} F\left(x_{l t}, y_{d t}\right)}{\left(f p_{t}-n w_{t}\right)}=\frac{\bar{\omega}_{t} \bar{s}_{t} f p_{t}}{\left(f p_{t}-n w_{t}\right)}=\frac{\bar{\omega}_{t}}{g\left(\varpi, \sigma_{0}\right)}=1.019
\end{aligned}
$$

Doing this produced the values $\varpi=0.65$ and $\sigma_{0}=0.23$. 
Table 4

Business cycle properties (1975:1-2011:2).

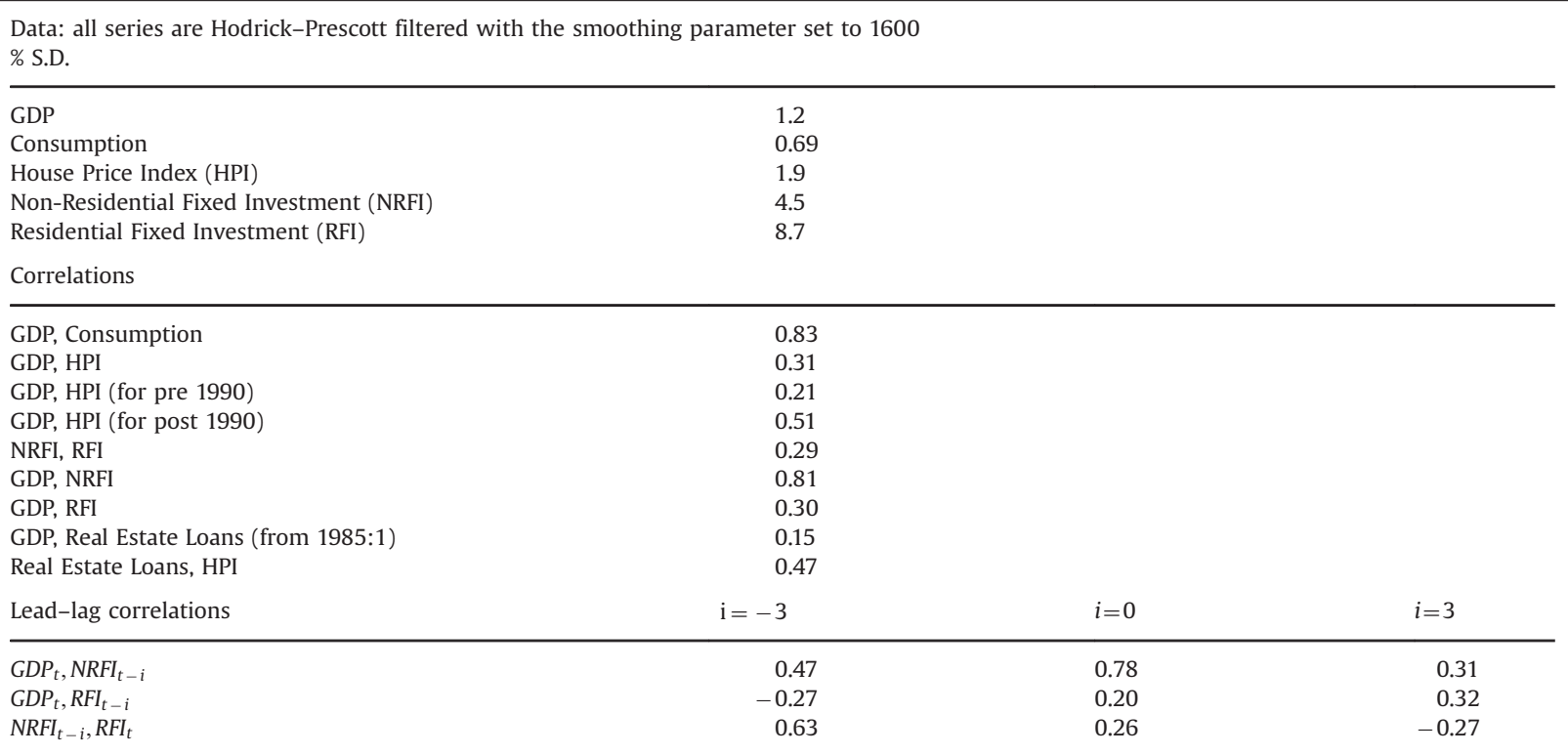

The entrepreneurial discount factor $\gamma$ can be recovered by the condition that the steady-state internal rate of return to the entrepreneur is offset by their additional discount factor:

$$
\gamma\left[\frac{\bar{s} f\left(\varpi, \sigma_{0}\right)}{1-\bar{s} g\left(\varpi, \sigma_{0}\right)}\right]=1
$$

and using the mark-up equation for $\bar{s}$ in Eq. (40), the parameter $\gamma$ then satisfies the relation

$$
\gamma=\frac{g_{U}}{g_{K}}\left[1+\frac{\phi\left(\varpi, \sigma_{0}\right)}{f^{\prime}\left(\varpi, \sigma_{0}\right)}\right] \approx 0.832
$$

where $g_{U}$ is the growth rate of marginal utility and $g_{K}$ is the growth rate of consumption (identical to the growth rate of capital on a balanced growth path).

The final two parameters are the adjustment cost parameters $\left(\kappa_{k}, \kappa_{h}\right)$. In their analysis of quarterly U.S. business cycle data, Christiano et al. (2005) provide estimates of $\kappa_{k}$ for different variants of their model which range over the interval $(0.91,3.24)$ (their model did not include housing and so there was no estimate for $\kappa_{h}$ ). Using these values as a crude benchmark and imposing the restriction that the adjustment cost parameter is the same for both stocks, we assume that $\left(\kappa_{h}, \kappa_{k}\right)$ take on the values $(0,3.0)$ implying that the elasticity of investment and housing with respect to a change in the respective shadow prices is 0.33 (i.e. the inverse of the adjustment cost parameter). As discussed below, the presence of adjustment costs improves the behavior of the model in several dimensions.

Table 4 presents some of the cyclical and statistical features of the U.S. economy for the period from 1975 through the second quarter of 2011 using quarterly data. ${ }^{23}$ As mentioned in the Introduction, the stylized facts for housing are readily seen. (i) Housing prices are much more volatile than output; (ii) residential investment is almost twice as volatile as nonresidential investment; (iii) GDP, consumption, the price of housing, non-residential investment and residential investment all co-move positively; (iv) and lastly, residential investment leads output by three quarters.

\section{Results}

\subsection{Steady state values, second moments and lead-lag patterns}

Table 5 shows some of the selected steady-state values (relative to steady-state GDP) from our model that includes the lending channel. These steady state values are broadly in line with the data. ${ }^{24}$

\footnotetext{
${ }^{23}$ Note that quarterly data is used here only to present some of the broad cyclical features of the data. We use annual data when calibrating the model In comparing the model output to the data, we employ annual data for this exercise.

${ }^{24} \mathrm{GDP}$ is calculated as $g d p_{t}=y_{c t}+p_{d t} y_{d t}+r_{h t} h_{t}$ where $r_{h t}$ is the rental rate of housing and is determined by the marginal rate of substitution between housing and consumption. Also note that private consumption $(P C E)$ and services includes the rental value of housing.
} 
Table 5

Steady-state values (relative to GDP).

\begin{tabular}{lll}
\hline Variables & Lending channel model & Davis and Heathcote $(\mathrm{D} \& \mathrm{H})$ \\
\hline Capital stock $(K)$ & 2.06 & 1.52 \\
Residential structures stock $\left(P_{d} \times S\right)$ & 1.14 & 1.00 \\
Private consumption $\left(P C E=c+r_{h} h\right)$ & 0.76 & 0.64 \\
Nonresidential investment $\left(i_{c}\right)$ & 0.19 & 0.14 \\
Residential investment $\left(i_{d}\right)$ & 0.05 & 0.04 \\
Construction $\left(b=p_{b} x_{b}\right)$ & 0.05 & 0.05 \\
Manufacturing $\left(m=p_{m} x_{m}\right)$ & 0.24 & 0.25 \\
Services $\left(p_{s} x_{s}+r_{h} h\right)$ & 0.71 & 0.71 \\
\hline
\end{tabular}

Our main interest is in the business cycle, i.e. second moment, properties of the model, and the roles that risk shocks and adjustment costs play in affecting these properties. To that end, we first examine the qualitative properties of the model using impulse response functions; we then turn to an analysis of equilibrium characteristics of the model by examining a set of second moments from data generated by the model.

\section{Equilibrium analysis}

\subsection{Dynamics: impulse response functions}

To analyze how the lending channel influences the effects of a risk shock, we initially analyze the model's impulse response functions to risk shocks under two different scenarios. In the first scenario, we set the monitoring cost parameter to zero $(\mu=0)$ while in the second scenario we use the value employed in the stochastic simulations $(\mu=0.25)$. With no monitoring costs, risk shocks should not influence the behavior of housing prices and residential investment (see Eqs. (40), (61), and (62)). We also examine the economy's response to an innovation to productivity in the construction sector (this being the most important input into the residential investment good). The impulse response functions (to a $1 \%$ innovation in both shocks) for a selected set of key variables are presented in Figs. 3-5. For all cases, both adjustment cost parameters are set equal to 3.0 .

The behavior of three key macroeconomic variables, namely GDP, household consumption (denoted PCE), and residential investment (denoted RESI) from this exercise is presented in Fig. 3. The response to a technology shock to the construction sector has the predicted effect that GDP increases. Consumption also increases, but only slightly, while investment responds dramatically (recall that this is in the presence of adjustment costs). This consumption/savings decision reflects agents response to the expected high productivity (due to the persistence of the shock) in the construction sector. Also note that monitoring costs (i.e. whether $\mu=0$ or $\mu=0.25$ ) play a rather insignificant role in the dynamic effects of a technology shock. And, as the model implies, when $\mu=0$, risk shocks have no effect on the economy. (For this reason, in Figs. 4 and 5, we report only the responses for $\mu=0.25$.) When $\mu=0.25$, a risk shock which affects housing production results in a modest fall in GDP but a relatively dramatic fall in residential investment. Recall, as discussed in the partial equilibrium analysis of the credit channel model, an increase in productivity risk results in a leftward shift in the supply of housing; since residential investment is the primary input into housing, it too falls in response to the increased risk. Consumption responds positively which is consistent with models that have an investment specific technology shock (e.g. Greenwood et al., 2000).

Fig. 4 reports the impulse response functions of the housing markup, the risk premium on loans to the housing producers and the bankruptcy rate. A positive technology shock to the construction sector increases the demand for housing and, ceteris paribus, will result in an increase in the price of housing. This will result in greater lending to the housing producers which will result in a greater bankruptcy rate and risk premium; both of these effects imply that the housing markup will increase. Note the counterfactual implication that both the bankruptcy rate and the risk premium on loans will be procyclical; this was also the case in the original Carlstrom and Fuerst (1997) model and for exactly the same reason. In contrast, a risk shock produces countercyclical behavior in these three variables. Hence, this argues for inclusion of risk shocks as an important impulse mechanism in the economy.

Finally, we report in Fig. 5 the impulse response functions of the prices of land and housing to the two shocks. A technology shock to the construction sector results in lower cost of housing inputs due to the increased output in residential investment so that the price of housing falls. However, the price of land, i.e. the fixed factor, increases. For an uncertainty shock, the resulting fall in the supply of housing causes the demand for the fixed factor (land) to fall and the price of the final good (housing) to increase.

\subsection{Quantitative analysis: risk shocks}

In order to examine the roles of risk shocks and the credit channel mechanism for house production, we compare simulated data generated under two scenarios. In the first case, only technology shocks to the intermediate sectors are present. This is identical to Davis and Heathcote's (2005) analysis and so the role of the lending mechanism is highlighted. 


\begin{tabular}{|c|c|}
\hline Technology Shock to Construction sector & $\underline{\text { Uncertainty Shock to Housing }}$ \\
\hline \multicolumn{2}{|c|}{$\begin{array}{c}\text { Developer } \\
\mu=0.25 \text { (monitoring cost: effects of agency cost) }\end{array}$} \\
$\mu=0$ (no monitoring cost: multi-sector model with housing and no agency cost) \\
\hline
\end{tabular}
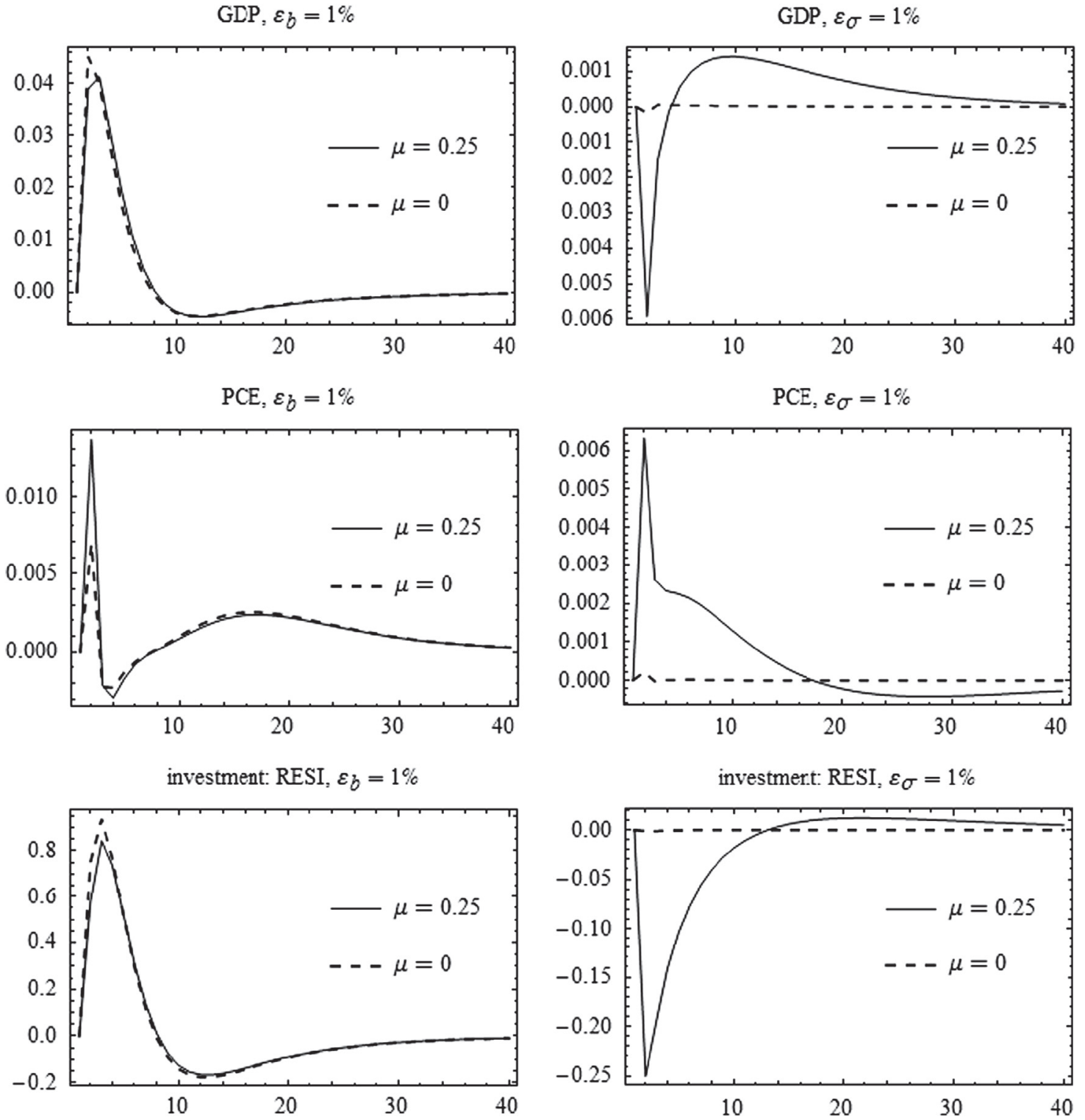

Fig. 3. Response of output, private consumption expenditure, and investment to $1 \%$ increase in sector (construction) technology shocks and uncertainty shocks (percentage deviations from steady-state values).

We then add risk shocks and set the volatility of the risk shocks to the calibrated value $\sigma_{\sigma}=0.15$. The results from this exercise are presented in Tables 6 and 7; also included in the tables are the corresponding values from Davis and Heathcote (2005) and the data; our analysis focuses on the same values as in Davis and Heathcote (2005) but we also include variables associated with the lending channel, namely the markup parameter, $\bar{s}$, and the risk premium on loans, $R P$. As a crude estimate of a $95 \%$ confidence interval, a two-standard deviation value is given and model values that fall within this range are reported in bold type.

As seen in Table 6, in the absence of risk shocks (see the first two columns) the model output is quite similar to that in Davis and Heathcote (2005). The main difference is that the lending channel mutes the volatility of residential 


\begin{tabular}{|c|c|}
\hline Technology Shock to Construction sector & Uncertainty Shock to Housing Developer \\
\hline$\mu=0.25$ (monitoring cost: effects of agency cost) \\
\hline
\end{tabular}
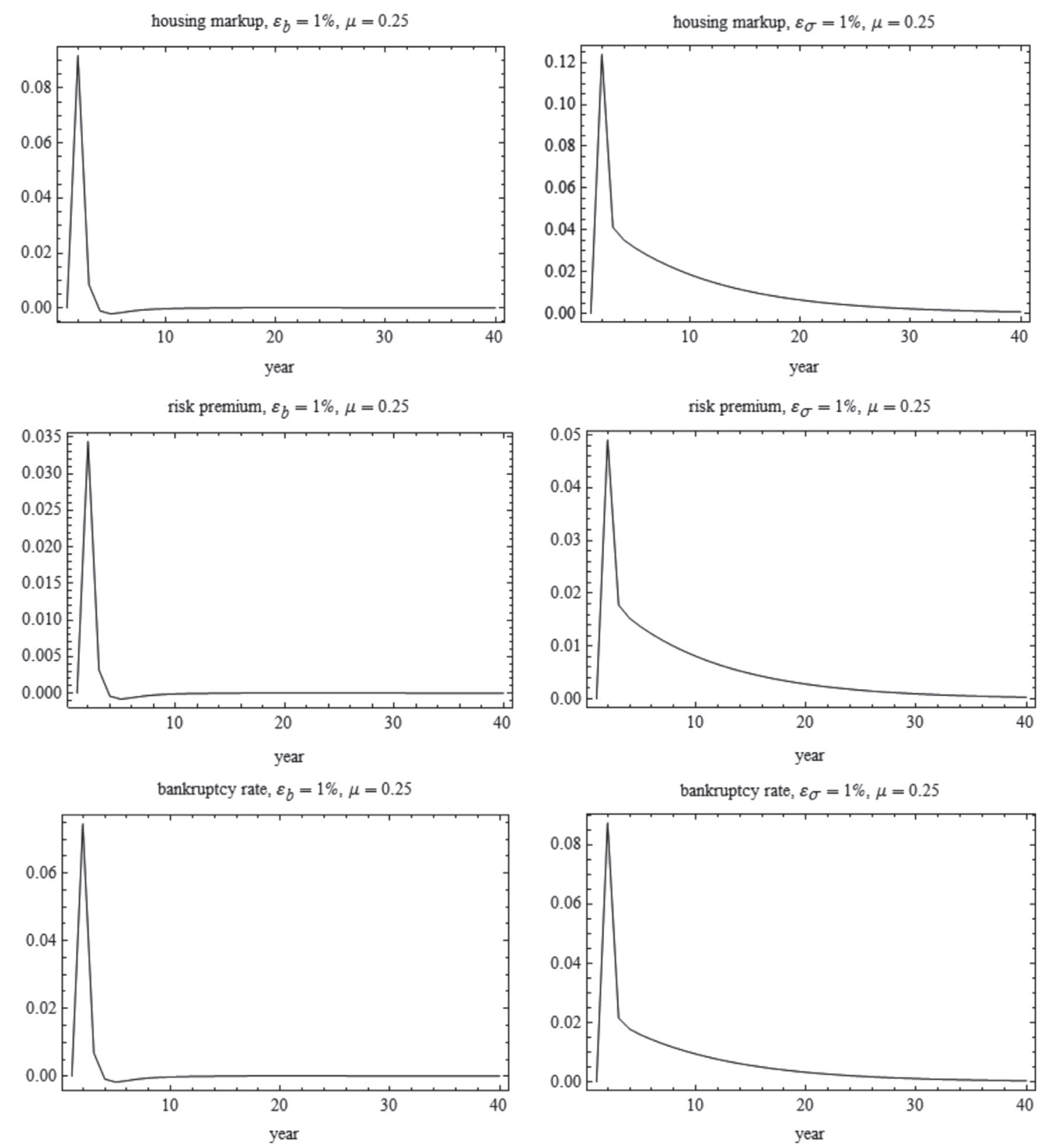

Fig. 4. Response of markup house price, risk premia, and bankruptcy rate to a $1 \%$ increase in sector (construction) technology shocks and uncertainty shocks (percentage deviations from steady-state values).

investment $\left(i_{d}\right){ }^{25}$ This is not surprising since, as discussed in Carlstrom and Fuerst (1997), the agency costs due to bankruptcy act as an endogenous adjustment cost. Hence, the volatility of housing investment falls. Moreover, a critical deficiency is that the model cannot replicate the volatility of housing prices $\left(p_{h}\right)$ (also true for the Davis and Heathcote, 2005

\footnotetext{
${ }^{25}$ While we do not report the values in the paper, the reduced volatility in residential investment is mirrored in the volatility of the related intermediate sectors. In particular, construction investment $\left(i_{b}\right)$ and manufacturing investment $\left(i_{m}\right)$ are too low in the housing channel model.
} 


\begin{tabular}{|r|c|}
\hline Technology Shock to Construction sector & Uncertainty Shock to Housing Developer \\
\hline$\mu=0.25$ \\
$\kappa_{k}=\kappa_{h}=3.0$ \\
\hline
\end{tabular}
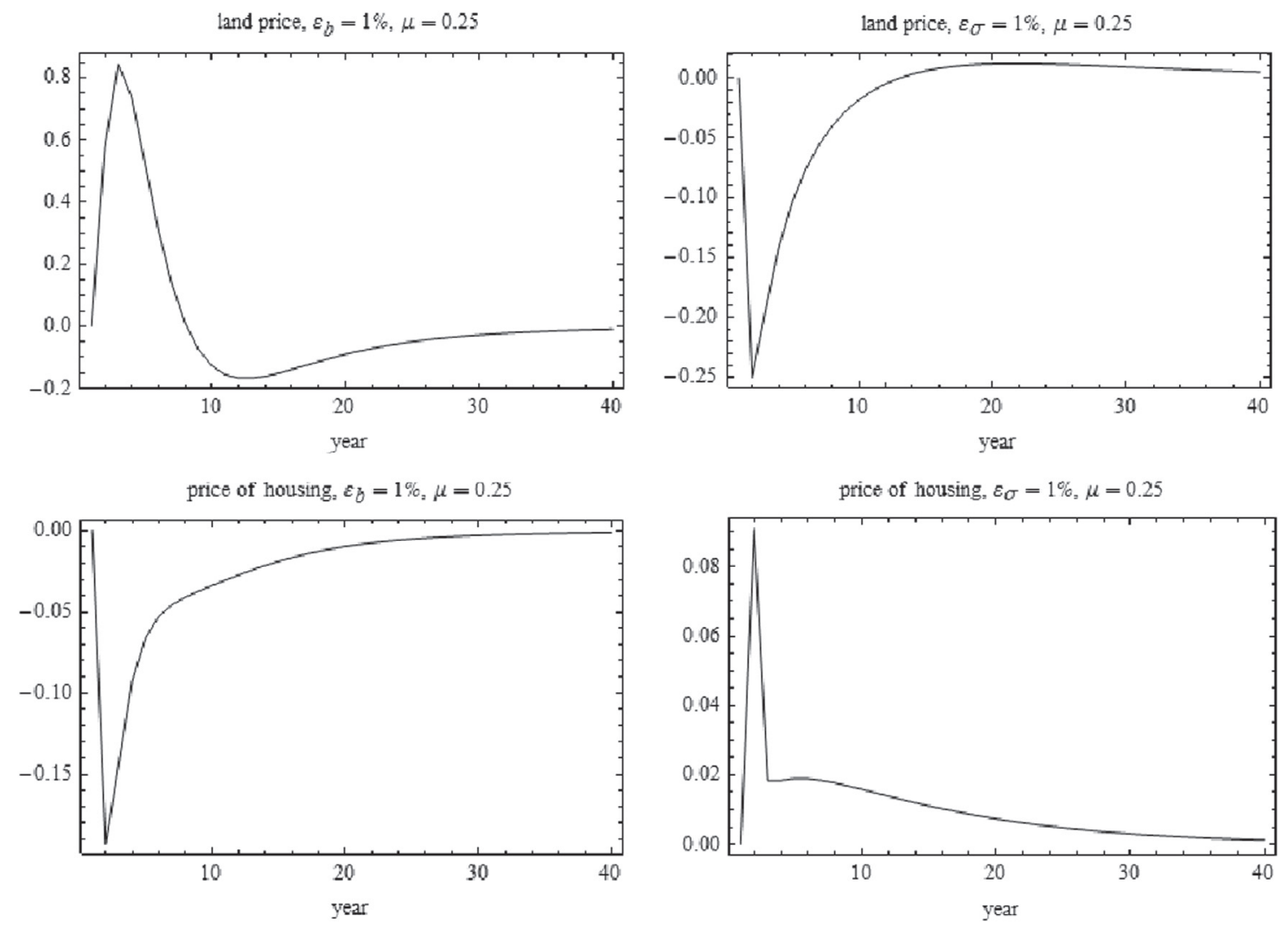

Fig. 5. Response of land price and house price to a $1 \%$ increase in sector (construction) technology shocks and uncertainty shocks (percentage deviations from steady-state values).

framework). It is also worth noting that the two variables introduced by the housing channel, namely the markup $(\bar{s})$ and the risk premium $(R P)$ exhibit much less volatility than seen in the data. The role of adjustment costs is seen and has the predicted effect; namely, the volatility of quantities decreases while prices become more volatile. Still, the volatility of housing prices is still much lower than observed.

With the addition of risk shocks (see column 3), the volatility of housing prices is increased but still lower than that seen in the data. Also, risk shocks produce volatility in residential investment $\left(i_{d}\right)$ that is greater than seen in the data. Timevarying uncertainty also results in a dramatic increase in the volatility of the markup and risk premium but the former variable is now too volatile while the latter remains too smooth relative to the data.

In the next iteration of the model, adjustment costs are added to both capital and housing production (column 4). As seen in Table 6 this improves the model in both price (i.e. volatility of housing prices) and quantity (i.e. volatility of residential investment) dimensions although residential investment becomes too smooth. Also, the volatility of the housing markup parameter is more in line with the data. However, the risk premium on loans to housing producers is still too volatile.

Turning to the contemporaneous correlations of some key variables as reported in Table 7, we again see that the housing cum lending channel model does not change too many of the features seen in the original Davis and Heathcote (2005) model. Note a key discrepancy between the data and both the lending channel model (with no risk shocks) and the Davis and Heathcote (2005) framework is the correlation between residential investment and housing prices: in the data these variables co-move positively while, in the models, they are negatively correlated. Adding risk shocks does not improve matters along this dimension but also produces counterfactual negative correlations between residential investment and consumption, $\operatorname{Corr}\left(i_{d}, P C E\right)$, and residential investment and housing prices, $\operatorname{Corr}\left(i_{d}, p_{h}\right)$. These results are not surprising in that all of the shocks (technology shocks and risk shocks) are primarily supply shocks so that a (relatively) stable demand 
Table 6

Standard deviations relative to standard deviation of GDP.

\begin{tabular}{|c|c|c|c|c|c|c|}
\hline \multirow{3}{*}{$\begin{array}{l}\text { Vars } \\
\sigma_{\sigma} \\
\kappa_{k}\end{array}$} & \multicolumn{4}{|c|}{ Lending channel model } & \multirow[t]{4}{*}{$(\mathrm{D} \& \mathrm{H})$} & \multirow[t]{4}{*}{ Data ( \pm 2 s.d.) (1948-2010) } \\
\hline & \multicolumn{2}{|l|}{0.0} & \multicolumn{2}{|l|}{0.15} & & \\
\hline & 0.0 & 3.0 & 0.0 & 3.0 & & \\
\hline$\kappa_{h}$ & 0.0 & 3.0 & 0.0 & 3.0 & & \\
\hline PCE & 0.53 & 1.02 & 0.53 & 1.03 & 0.48 & $0.82( \pm 0.15)$ \\
\hline$N$ & 0.37 & 0.18 & 0.38 & 0.21 & 0.41 & $1.01( \pm 0.18)$ \\
\hline$i_{c}$ & 3.05 & 1.29 & 3.20 & 1.29 & 3.21 & $4.16( \pm 0.75)$ \\
\hline$i_{d}$ & 2.95 & 1.42 & 6.30 & 1.49 & 6.12 & $5.04( \pm 0.91)$ \\
\hline$p_{h}$ & 0.39 & 0.95 & 0.43 & 2.29 & 0.4 & $2.08( \pm 0.44)$ \\
\hline $\bar{s}$ & 0.28 & 0.15 & 0.88 & 2.23 & & $3.97( \pm 0.83)$ \\
\hline$R P$ & 0.11 & 0.06 & 0.39 & 0.94 & & $0.26( \pm 0.08)$ \\
\hline
\end{tabular}

Table 7

Correlations.

\begin{tabular}{|c|c|c|c|c|c|c|}
\hline \multirow{3}{*}{$\begin{array}{l}\text { Vars } \\
\sigma_{\sigma} \\
\kappa_{k}\end{array}$} & \multicolumn{4}{|c|}{ Lending channel model } & \multirow[t]{4}{*}{$(\mathrm{D} \& \mathrm{H})$} & \multirow[t]{4}{*}{ Data ( \pm 2 s.d.) $(1948-2010)$} \\
\hline & \multicolumn{2}{|l|}{0.0} & \multicolumn{2}{|l|}{0.15} & & \\
\hline & 0.0 & 3.0 & 0.0 & 3.0 & & \\
\hline$\kappa_{h}$ & 0.0 & 3.0 & 0.0 & 3.0 & & \\
\hline$(G D P, P C E)$ & 0.97 & 0.97 & 0.97 & 0.96 & 0.95 & $0.82(+0.067,-0.10)$ \\
\hline$\left(G D P, p_{h}\right)$ & 0.77 & 0.37 & 0.67 & 0.20 & 0.65 & $0.67(+0.15,-0.23)$ \\
\hline$\left(i_{c}, P C E\right)$ & 0.90 & 0.65 & 0.86 & 0.64 & 0.91 & $0.46(+0.17,-0.22)$ \\
\hline$\left(i_{d}, P C E\right)$ & 0.42 & 0.65 & 0.17 & 0.61 & 0.26 & $0.66(+0.12,-0.17)$ \\
\hline$\left(i_{c}, i_{d}\right)$ & 0.26 & 0.84 & -0.17 & 0.80 & 0.15 & $0.25(+0.22,-0.25)$ \\
\hline$\left(i_{d}, p_{h}\right)$ & 0.018 & 0.56 & -0.37 & 0.23 & -0.20 & $0.34(+0.20,-0.24)$ \\
\hline$\left(\bar{s}, p_{h}\right)$ & -0.15 & 0.39 & 0.37 & 0.92 & & $0.15(+0.30,-0.33)$ \\
\hline$(\bar{s}, G D P)$ & 0.17 & 0.25 & 0.01 & 0.07 & & $0.09(+0.31,-0.33)$ \\
\hline$(R P, G D P)$ & 0.17 & 0.25 & 0.00 & 0.07 & & $-0.21(+0.57,-0.46)$ \\
\hline
\end{tabular}

Table 8

Lead-lag patterns.

\begin{tabular}{|c|c|c|c|c|}
\hline \multirow{3}{*}{$\begin{array}{l}\text { Variables } \\
\text { Adjustment cost } \kappa_{k} \\
\text { Adjustment cost } \kappa_{h}\end{array}$} & \multicolumn{2}{|c|}{ Lending channel model } & \multirow[t]{3}{*}{$\mathrm{D} \& \mathrm{H}$} & \multirow[t]{3}{*}{ Data ( \pm 2 s.d.) } \\
\hline & 0.0 & 3.0 & & \\
\hline & 0.0 & 3.0 & & \\
\hline$\left(i_{c}[-1], G D P[0]\right)$ & 0.53 & 0.31 & 0.45 & $0.17(+0.21,-0.25)$ \\
\hline$\left(i_{c}[0], G D P[0]\right)$ & 0.89 & 0.80 & 0.94 & $0.72(+0.01,-0.14)$ \\
\hline$\left(i_{c}[1], G D P[0]\right)$ & 0.31 & 0.82 & 0.33 & $0.37(+0.19,-0.23)$ \\
\hline$\left(i_{d}[-1], G D P[0]\right)$ & 0.07 & 0.33 & 0.19 & $0.52(+0.16,-0.21)$ \\
\hline$\left(i_{d}[0], G D P[0]\right)$ & 0.27 & 0.75 & 0.44 & $0.47(+0.17,-0.22)$ \\
\hline$\left(i_{d}[1], G D P[0]\right)$ & 0.23 & 0.64 & 0.14 & $-0.22(+0.25,-0.22)$ \\
\hline$\left(i_{c}[-1], i_{d}[0]\right)$ & 0.21 & 0.57 & 0.07 & $-0.37(+0.24,-0.20)$ \\
\hline$\left(i_{c}[0], i_{d}[0]\right)$ & -0.17 & 0.80 & 0.15 & $0.25(+0.22,-0.25)$ \\
\hline$\left(i_{c}[1], i_{d}[0]\right)$ & 0.01 & 0.68 & 0.08 & $0.53(+0.16,-0.21)$ \\
\hline
\end{tabular}

curve for housing is observed. Also, risk shocks are akin to a investment specific technology shock which typically moves investment and consumption in opposite directions (e.g. Greenwood et al., 2000). However, with the introduction of adjustment costs, all correlations become positive and, moreover, $\operatorname{Corr}\left(i_{d}, P C E\right)$ and $\operatorname{Corr}\left(i_{d}, p_{h}\right)$ fall within the $95 \%$ confidence intervals. While the correlation of investment in both stocks (capital and housing) becomes positive with adjustment costs, it is too high. Note that the correlation between the markup variable and housing prices becomes positive in the presence of risk shocks and the risk premium is negatively correlated with GDP; both of these features are seen in the data (but the latter correlation is clearly not precisely estimated). On a less positive note, the markup and GDP are negatively correlated in the model with risk shocks but the correlation is within the confidence interval estimated from the data.

The last set of housing stylized facts that is in question is the lead-lag patterns of residential and non-residential investments. Table 8 shows the result for the model with risk shocks only $\left(\sigma_{\sigma}=0.15\right)$. As pointed out in the early business cycle analysis by Burns and Mitchell (1946), residential investment leads non-residential business investment over the 
Table 9

Variance decomposition.

\begin{tabular}{llr}
\hline Variable & Shock & \multicolumn{1}{l}{$\%$} \\
\hline Gross domestic product $(G D P)$ & $u_{b}$ & 4.38 \\
& $u_{m}$ & 58.31 \\
& $u_{s}$ & 36.96 \\
Private consumption $(P C E)$ & $u_{\sigma}$ & 0.36 \\
& $u_{b}$ & 5.61 \\
& $u_{m}$ & 57.48 \\
& $u_{s}$ & 36.45 \\
Labor $(N)$ & $u_{\sigma}$ & 0.46 \\
& $u_{b}$ & 12.08 \\
& $u_{m}$ & 42.32 \\
Nonresidential investment $\left(i_{c}\right)$ & $u_{s}$ & 21.98 \\
& $u_{\sigma}$ & 23.62 \\
& $u_{b}$ & 4.33 \\
& $u_{m}$ & 60.86 \\
Residential investment $\left(i_{d}\right)$ & $u_{s}$ & 34.77 \\
& $u_{\sigma}$ & 0.04 \\
& $u_{b}$ & 30.49 \\
& $u_{m}$ & 37.71 \\
House price $\left(p_{h}\right)$ & $u_{s}$ & 23.23 \\
& $u_{\sigma}$ & 8.58 \\
& $u_{b}$ & 12.26 \\
Risk premium $(R P)$ & $u_{m}$ & 1.52 \\
Markup $(\bar{s})$ & $u_{s}$ & 3.33 \\
& $u_{\sigma}$ & 82.89 \\
& $u_{b}$ & 0.07 \\
& $u_{m}$ & 0.18 \\
& $u_{s}$ & 0.14 \\
& $u_{\sigma}$ & 99.61 \\
& $u_{b}$ & 0.07 \\
& $u_{m}$ & 0.16 \\
& $u_{s}$ & 0.13 \\
& $u_{\sigma}$ & 99.64 \\
\hline & & \\
& &
\end{tabular}

business cycle. As in Davis and Heathcote (2005), the lending channel model also fails to reproduce this key feature in the data. Consequently, the propagation mechanism of agency costs model does amplify prices and other real variables, but does not contribute in explaining the lead-lag features.

As a final analysis of the model, we do a variance decomposition (analytically) of the model by using a Cholesky decomposition of the industrial production shocks $\left(u_{b}, u_{m}, u_{s}\right)$ using that respective ordering. (For expository reasons, we report only the results for the model with risk shocks and adjustment costs in both housing and capital.) This resulted in the following estimated structure (we assume that the innovations to the risk shocks are i.i.d.):

$$
\begin{aligned}
& u_{b}=\varepsilon_{b} \\
& u_{m}=\varepsilon_{m}-0.066 \varepsilon_{b} \\
& u_{s}=\varepsilon_{s}-0.105 \varepsilon_{b}-0.164 \varepsilon_{m} \\
& u_{\sigma}=\varepsilon_{\sigma}
\end{aligned}
$$

With this decomposition and assuming that the covariance matrix of the vector $u=\left(u_{b}, u_{m}, u_{s}, u_{\sigma}\right)$ is given by

$$
\Sigma_{u}=\left(\begin{array}{cccc}
\sigma_{b}^{2} & 0 & 0 & 0 \\
0 & \sigma_{m}^{2} & 0 & 0 \\
0 & 0 & \sigma_{s}^{2} & 0 \\
0 & 0 & 0 & \sigma_{\sigma}^{2}
\end{array}\right),
$$

all second moments in the model can be expressed as linear combinations of the variances $\sigma_{i}, i=(b, s, m . \sigma)$. The resulting variance decompositions are given in Table 9.

Note that, as expected, uncertainty shocks account for a large fraction of the variation in variables related to the housing sector, most notably residential investment (almost $80 \%$ of the variation is due to uncertainty shocks) and housing prices (contributing over $90 \%$ of the volatility in housing prices). Also the volatility of both the risk premium associated with bank loans and the housing markup is almost entirely explained by risk shocks. For other aggregate variables such as GDP and private consumption, uncertainty shocks do not play a large quantitative role but this is not that surprising given that the other shocks directly influence the supply of intermediate goods. 
Table 10

Standard deviations relative to standard deviation of GDP.

\begin{tabular}{llll}
\hline \multirow{2}{*}{ Vars } & \multicolumn{2}{l}{ Risk and demand shocks } & Data $( \pm 2$ s.d. $)$ \\
\cline { 2 - 3 }$\kappa_{k}$ & 0.0 & 3 & \\
$\kappa_{h}$ & 0.0 & 3 & \\
\hline \multirow{2}{*}{$P C E$} & 0.56 & 1.04 & $0.82( \pm 0.15)$ \\
$N$ & 0.39 & 0.22 & $1.01( \pm 0.18)$ \\
$i_{c}$ & 3.01 & 1.16 & $4.16( \pm 0.75)$ \\
$i_{d}$ & 8.21 & 3.06 & $5.04( \pm 0.91)$ \\
$p_{h}$ & 0.92 & $\mathbf{2 . 0 8}$ & $2.08( \pm 0.44)$ \\
$\bar{S}$ & 0.96 & 2.01 & $3.97( \pm 0.83)$ \\
$R P$ & 0.41 & 0.85 & $0.26( \pm 0.08)$ \\
\hline
\end{tabular}

\subsection{Quantitative analysis: adding demand shocks}

In order to further assess the quantitative importance of uncertainty shocks, we introduce stochastic demand shocks similar to that used my Iacoviello and Neri (2010). Since that analysis demonstrated that housing demand shocks can explain many features of the housing market, the question is raised about the relative importance of the two shocks. To investigate this, we modify consumer preferences (as given in Eq. (12)) so that the weight on housing in utility is stochastic. Specifically, it is assumed that preferences are given by

$$
U\left(c_{t}, h_{t}, 1-n_{t}\right)=\frac{\left(c_{t}^{\mu_{c}} h_{t}^{\mu_{h, t}}\left(1-n_{t}\right)^{1-\mu_{c}-\bar{\mu}_{h}}\right)^{1-\psi}}{1-\psi}
$$

The stochastic process for the demand shock is assumed to be

$$
\mu_{h, t+1}=\left(1-\rho_{h}\right) \bar{\mu}_{h}+\rho_{h} \mu_{h, t}+\varepsilon_{h, t+1}
$$

Note that our analysis is very much a perturbation approach in that we do not impose that the coefficients in the utility function always sum to unity; this is only true on average. In this way we do not impose any negative correlation between the demand for housing and consumption and/or leisure in the stochastic setting. Solving the model yields new policy functions for all endogenous variables with the demand shock, $\mu_{h, t}$, as an additional state variable.

Parameter values were chosen so that preferences were, on average, the same as in the previous analysis. That is, we chose $\psi=2$ and $\bar{\mu}_{h}=0.044$. Using a slightly different model for demand shocks, Iacoviello and Neri (2010) estimated an autoregressive parameter of $\rho_{h}=0.96$. We also employed that parameter and, after log-linearizing the equilibrium necessary conditions, solved for the equilibrium policy functions. We then used the policy functions to calibrate the volatility of the housing shock, $\sigma_{h}$. Specifically, we chose the standard deviation of housing demand so that the standard deviation of housing prices relative to that of GDP matched the data (using the value of $\sigma_{\sigma}=0.15$ used in the previous section). This resulted in an estimate of $\sigma_{h}=0.04 .^{26}$

This model produced the analogs to Tables 6-9. Turning first to the relative volatilities (see Table 10), note that the volatility of housing prices matches perfectly that seen in the data; this is clearly a product of our calibration. The main improvement is that residential investment, with demand shocks and adjustment costs, is closer to that seen in the data but still too low.

The main influence of demand shocks is seen in the contemporaneous correlations reported in Table 11. Even without adjustment costs, the correlation of housing prices with both GDP and residential investment $\left(i_{d}\right)$ is positive as seen in the data. This corroborates other work, e.g. Iacoviello (2005), in that stochastic housing demand is an important factor in explaining housing price dynamics.

For completeness, the dynamics of residential and capital investment are reported in Table 12; the addition of demand shocks does not help the model in explaining the lead-lag structure of residential and business investment.

Finally, we report the variance decomposition from the VAR analysis as in the preceding section (see Table 13). For the movements of all quantities, demand shocks play a much more significant role than uncertainty shocks. However, roughly $80 \%$ of the movements in housing prices are explained by uncertainty shocks. And, as in the model without demand shocks, time varying uncertainty accounts for most of the volatility seen in the risk premium and housing price markup factor.

\subsection{Some final remarks}

Our primary findings fall into two broad categories. First, risk shocks to the housing producing sector imply a quantitatively large role for uncertainty in explaining housing prices. In particular, the model can account for the

\footnotetext{
${ }^{26}$ Using a richer model with heterogeneous agents, a slightly different specification of housing demand shocks, and employing a Bayesian estimation strategy, Iacoviello and Neri (2010) estimated $\sigma_{h}$ ( $\sigma_{j}$ in their notation) to be 0.0416 ; surprisingly close to our calibrated estimate
} 
Table 11

Correlations.

\begin{tabular}{lccr}
\hline \multirow{2}{*}{ Vars } & \multicolumn{2}{l}{ Risk and demand shocks } & \multicolumn{1}{l}{ Data $( \pm 2$ s.d. $)$} \\
\cline { 2 - 3 }$\kappa_{k}$ & 0.0 & 3 & \\
$\kappa_{h}$ & 0.0 & 3 & $0.82(+0.07,-0.10)$ \\
\hline PCE, GDP & 0.97 & 0.96 & $0.67(+0.15,-0.23)$ \\
$p_{h}, G D P$ & $\mathbf{0 . 6 3}$ & 0.25 & $0.46(+0.17,-0.22)$ \\
$P C E, i_{c}$ & 0.69 & $\mathbf{0 . 5 9}$ & $0.66(+0.12,-0.17)$ \\
$P C E, i_{d}$ & 0.42 & 0.47 & $0.25(+0.22,-0.25)$ \\
$i_{c}, i_{d}$ & -0.24 & $\mathbf{0 . 3 3}$ & $0.34(+0.20,-0.24)$ \\
$p_{h}, i_{d}$ & $\mathbf{0 . 4 2}$ & $\mathbf{0 . 2 2}$ & $0.15(+0.30,-0.33)$ \\
$\bar{s}, p_{h}$ & 0.46 & 0.91 & $0.09(+0.31,-0.33)$ \\
$\bar{s}, G D P$ & $\mathbf{0 . 1 2}$ & $\mathbf{0 . 0 8}$ & $-0.21(+0.57,-0.46)$ \\
$R P, G D P$ & $\mathbf{0 . 1 1}$ & $\mathbf{0 . 0 8}$ & \\
\hline
\end{tabular}

Table 12

Lead-lag patterns; risk and demand shocks.

\begin{tabular}{lccr}
\hline \multirow{2}{*}{ Vars } & \multicolumn{2}{l}{ Risk and demand shocks } & \multirow{2}{*}{ Data $( \pm 2$ s.d. $)$} \\
\cline { 2 - 3 }$\kappa_{k}$ & 0.0 & 3 & \\
$\kappa_{h}$ & 0.0 & 3 & $0.17(+0.23,-0.25)$ \\
\hline$i_{c}(-1), G D P(0)$ & 0.46 & $\mathbf{0 . 3 0}$ & $0.72(+0.10,-0.14)$ \\
$i_{c}(0), G D P(0)$ & $\mathbf{0 . 7 3}$ & $\mathbf{0 . 7 3}$ & $0.37(+0.19,-0.24)$ \\
$i_{c}(1), G D P(0)$ & 0.14 & 0.73 & $0.52(+0.16,-0.21)$ \\
$i_{d}(-1), G D P(0)$ & 0.18 & 0.24 & $0.47(+0.17,-0.22)$ \\
$i_{d}(0), G D P(0)$ & $\mathbf{0 . 4 5}$ & $\mathbf{0 . 6 0}$ & $-0.22(+0.25,-0.22)$ \\
$i_{d}(1), G D P(0)$ & 0.40 & 0.58 & $-0.37(+0.24,-0.20)$ \\
$i_{c}(-1), i_{d}(0)$ & 0.14 & 0.26 & $0.25(+0.22,-0.25)$ \\
$i_{c}(0), i_{d}(0)$ & -0.24 & $\mathbf{0 . 3 3}$ & $0.53(+0.16,-0.21)$ \\
$i_{c}(1), i_{d}(0)$ & -0.20 & 0.24 & \\
\hline
\end{tabular}

Table 13

Variance decomposition.

\begin{tabular}{|c|c|c|}
\hline Variable & Shock & $\%$ \\
\hline \multirow[t]{5}{*}{ Gross domestic product (GDP) } & $u_{b}$ & 3.76 \\
\hline & $u_{m}$ & 46.82 \\
\hline & $u_{s}$ & 29.54 \\
\hline & $u_{h}$ & 19.65 \\
\hline & $u_{\sigma}$ & 0.23 \\
\hline \multirow[t]{5}{*}{ Private consumption $(P C E)$} & $u_{b}$ & 4.28 \\
\hline & $u_{m}$ & 45.41 \\
\hline & $u_{s}$ & 28.76 \\
\hline & $u_{h}$ & 21.22 \\
\hline & $u_{\sigma}$ & 0.34 \\
\hline \multirow[t]{5}{*}{ Labor $(N)$} & $u_{b}$ & 8.08 \\
\hline & $u_{m}$ & 31.15 \\
\hline & $u_{s}$ & 16.17 \\
\hline & $u_{h}$ & 31.47 \\
\hline & $u_{\sigma}$ & 13.13 \\
\hline \multirow[t]{5}{*}{ Nonresidential investment $\left(i_{c}\right)$} & $u_{b}$ & 4.19 \\
\hline & $u_{m}$ & 59.00 \\
\hline & $u_{s}$ & 35.77 \\
\hline & $u_{h}$ & 0.99 \\
\hline & $u_{\sigma}$ & 0.05 \\
\hline \multirow[t]{5}{*}{ Residential investment $\left(i_{d}\right)$} & $u_{b}$ & 5.45 \\
\hline & $u_{m}$ & 7.67 \\
\hline & $u_{s}$ & 4.09 \\
\hline & $u_{h}$ & 80.87 \\
\hline & $u_{\sigma}$ & 1.92 \\
\hline \multirow[t]{5}{*}{ House price $\left(p_{h}\right)$} & $u_{b}$ & 11.22 \\
\hline & $u_{m}$ & 1.79 \\
\hline & $u_{s}$ & 3.54 \\
\hline & $u_{h}$ & 2.94 \\
\hline & $u_{\sigma}$ & 80.52 \\
\hline
\end{tabular}


Table 13 (continued)

\begin{tabular}{llr}
\hline Variable & Shock & $\%$ \\
\hline Markup $(\bar{s})$ & $u_{b}$ & 0.02 \\
& $u_{m}$ & 0.25 \\
& $u_{s}$ & 0.17 \\
& $u_{h}$ & 1.51 \\
Risk premium $(R P)$ & $u_{\sigma}$ & 98.06 \\
& $u_{b}$ & 0.02 \\
& $u_{m}$ & 0.23 \\
& $u_{s}$ & 0.16 \\
& $u_{h}$ & 1.38 \\
\hline
\end{tabular}

observation that housing prices are more volatile than output. However, demand shocks are critical in order to match contemporaneous correlation of housing prices with GDP and residential investment and to help explain the volatility in real quantities. The lead-lag pattern of residential and non-residential, however, is not reconciled within our framework. ${ }^{27}$

For future research, modeling uncertainty due to time variation in the types of entrepreneurs would be fruitful. One possibility would be an economy with a low risk agent whose productivity shocks exhibit low variance and a high risk agent with a high variance of productivity shocks. Because of restrictions on the types of financial contracts that can be offered, the equilibrium is a pooling equilibrium so that the same type of financial contract is offered to both types of agents. Hence the aggregate distribution for technology shocks hitting the entrepreneurial sector is a mixture of the underlying distributions for each type of agent. Our conjecture is that this form of uncertainty has important quantitative predictions and, hence, could be an important impulse mechanism in the credit channel literature that, heretofore, has been overlooked. It also anecdotally corresponds with explanations for the cause of the current credit crisis: a substantial fraction of mortgage borrowers had higher risk characteristics than originally thought.

\section{Acknowledgments}

We wish to thank David Dejong, Aleks Berenten, Andreas Hornstein, Stephen LeRoy, Alejandro Badel, and two anonymous referees for useful comments and suggestions. We also benefitted from comments received during presentations at: the Humboldt University, University of Basel, European Business School, Latin American Econometric Society Meeting 2009, AREUEA 2010, University of Wisconsin-Madison and Federal Reserve Bank of Chicago: Housing-Labor-MacroUrban Conference April 2010 and SED July 2010. We are especially indebted to participants in the UC Davis and IHS Macroeconomics Seminar for insightful suggestions that improved the exposition of the paper. We also gratefully acknowledge financial support from Jubiläumsfonds der Oesterreichischen Nationalbank (Jubiläumsfondsprojekt Nr. 14667) and Deutsche Forschungsgemeinschaft (DFG Nr. LE 1545/1-1).

\section{Appendix A. Equilibrium equations}

Equilibrium in the economy is defined by the following set of equations:

Factor demand optimality in the intermediate goods markets

$$
\begin{aligned}
& r_{t}=\theta_{i} \frac{p_{i t} x_{i t}}{k_{i t}} \quad \text { (3 equations) } \\
& w_{t}=\left(1-\theta_{i}\right) \frac{p_{i t} x_{i t}}{n_{i t}} \quad \text { (3 equations) }
\end{aligned}
$$

Factor demand optimality in the final goods sector:

$$
\begin{aligned}
& p_{c t} y_{c t}=\frac{p_{b t} b_{c t}}{B_{c}}=\frac{p_{m t} m_{c t}}{M_{c}}=\frac{p_{s t} s_{c t}}{S_{c}} \quad(3 \text { equations) } \\
& p_{d t} y_{d t}=\frac{p_{b t} b_{d t}}{B_{d}}=\frac{p_{m t} m_{d t}}{M_{d}}=\frac{p_{s t} s_{d t}}{S_{d}} \quad(3 \text { equations })
\end{aligned}
$$

\footnotetext{
${ }^{27}$ Fisher (2007) presents a model with household production which does produce the lead-lag pattern observed in residential and non-residential investments.
} 
Factor demand in the housing sector (using the fact that, in equilibrium $x_{l t}=1$ ) produces two more equations:

$$
\begin{aligned}
\frac{p_{l t}}{p_{h t}} & =\frac{(1-\zeta) y_{d t}^{\zeta}}{\bar{s}_{t}} \\
\frac{p_{d t}}{p_{h t}} & =\frac{\zeta y_{d t}^{\zeta-1}}{\bar{s}_{t}}
\end{aligned}
$$

The household's necessary conditions provide 5 more equations:

$$
\begin{aligned}
& 1=q_{k t} G_{1}\left(i_{k t}, i_{k t-1}\right)+\beta \eta E_{t}\left[\frac{U_{1 t+1}}{U_{1 t}} q_{k t+1} G_{2}\left(i_{k t+1}, i_{k t}\right)\right] \\
& q_{k t}=\beta \eta E_{t}\left[\frac{U_{1 t+1}}{U_{1 t}}\left(r_{t+1}+q_{k t+1}(1-\delta)\right)\right] \\
& p_{h t}=q_{h t} G_{1}\left(i_{h t}, i_{h t-1}\right)+\beta \eta E_{t}\left[q_{h t+1} G_{2}\left(i_{h t+1}, i_{h t}\right) \frac{U_{1 t+1}}{U_{1 t}}\right] \\
& q_{h t}=\beta \eta E_{t}\left[\left(1-\delta_{h}\right) q_{h t+1} \frac{U_{1 t+1}}{U_{1 t}}+\frac{U_{2 t+1}}{U_{1 t}}\right] \\
& w_{t}=\frac{U_{3}\left(c_{t}, h_{t}, 1-n_{t}\right)}{U_{1}\left(c_{t}, h_{t}, 1-n_{t}\right)} .
\end{aligned}
$$

The financial contract provides the condition for the markup and the incentive compatibility constraint:

$$
\begin{aligned}
& \bar{s}_{t}^{-1}=\left[\left(f\left(\bar{\omega}_{t} ; \sigma_{\omega, t}\right)+g\left(\bar{\omega}_{t} ; \sigma_{\omega, t}\right)\right)+\frac{\phi\left(\bar{\omega}_{t} ; \sigma_{\omega, t}\right) \mu f\left(\bar{\omega}_{t} ; \sigma_{\omega, t}\right)}{\frac{\partial f\left(\bar{\omega}_{t} ; \sigma_{\omega, t}\right)}{\partial \bar{\omega}_{t}}}\right] \\
& p_{h t} y_{d t}^{\zeta}=k_{t}^{e} \frac{\left(r_{t}+1-\delta_{\kappa}\right)}{1-\bar{s}_{t} g\left(\bar{\omega}_{t} ; \sigma_{\omega, t}\right)} \bar{s}_{t}
\end{aligned}
$$

The entrepreneur's maximization problem provides the following Euler equation:

$$
1=\beta \eta \gamma E_{t}\left[\left(r_{t+1}+1-\delta_{\kappa}\right) \frac{\bar{s}_{t+1} f\left(\bar{\omega}_{t+1} ; \sigma_{\omega, t+1}\right)}{1-\bar{s}_{t+1} g\left(\bar{\omega}_{t+1} ; \sigma_{\omega, t+1}\right)}\right]
$$

To these optimality conditions, we have the following market clearing conditions:

Labor market clearing:

$$
n_{t}=\sum_{i} n_{i t}, \quad i=b, m, s
$$

Market clearing for capital:

$$
k_{t}=\sum_{i} k_{i t}, \quad i=b, m, s
$$

Market clearing for intermediate goods:

$$
x_{b t}=b_{c t}+b_{d t}, \quad x_{m t}=m_{c t}+m_{d t}, \quad x_{s t}=s_{c t}+s_{d t} .
$$

The aggregate resource constraint for the consumption final goods sector (i.e. the law of motion for capital)

$$
\eta k_{t+1}=\left(1-\delta_{\kappa}\right) k_{t}+G\left(i_{k t}, i_{k t-1}\right)
$$

The law of motion for the effective housing units:

$$
\eta h_{t+1}=\left(1-\delta_{h}\right) h_{t}+G\left(i_{h t}, i_{h t-1}\right)
$$

The law of motion for entrepreneur's capital stock:

$$
\eta k_{t+1}^{e}=k_{t}^{e} \frac{\left(r_{t}+1-\delta_{\kappa}\right)}{1-\bar{s}_{t} g\left(\bar{\omega}_{t} ; \sigma_{\omega, t}\right)} \bar{s}_{t} f\left(\bar{\omega}_{t} ; \sigma_{\omega, t}\right)-c_{t}^{e}
$$

Finally, we have the production functions. Specifically, for the intermediate goods markets:

$$
x_{i t}=k_{i t} \theta_{i}\left(n_{i t} \exp ^{z_{i t}}\right)^{1-\theta_{i}} ; \quad i=b, m, s
$$


For the final goods sectors, we have

$$
\begin{aligned}
& y_{c t}=b_{c t}^{B_{c}} m_{c t}^{M_{c}} s_{c t}^{S_{c}} \\
& y_{d t}=b_{d t}^{B_{d}} m_{d t}^{M_{d}} s_{d t}^{S_{d}}
\end{aligned}
$$

These provide the required 35 equations to solve for equilibrium. In addition there are the laws of motion for the technology shocks and the uncertainty shocks:

$$
\begin{aligned}
& \tilde{\mathbf{z}}_{t+1}=B \cdot \tilde{\mathbf{z}}_{t}+\vec{\varepsilon}_{t+1} \\
& \sigma_{\omega, t+1}=\sigma_{0}^{1-\chi} \sigma_{\omega, t}^{\chi} \exp ^{\varepsilon_{\sigma, t+1}}
\end{aligned}
$$

To solve the model, we log linearize around the steady-state. The solution is defined by 35 equations in which the endogenous variables are expressed as linear functions of the vector of state variables $\left(z_{b t}, z_{m t}, z_{s t}, \sigma_{\omega t}, k_{t}, k_{t}^{e}, h_{t}\right)$.

\section{Appendix B. Data appendix}

- Loans: Federal Reserve Board, Statistics: Releases and Historical Data Assets and Liabilities of Commercial Banks in the U. S. - h.8. Seasonally adjusted, adjusted for mergers, billions of dollars. http://www.federalreserve.gov/releases/h8/data. htm

- Total Loans: Total loans and leases at commercial banks.

- Residential Real Estate Loans: Loans to residential sector excluding revolving home equity loans.

- Commercial Real Estate Loans: Loans to commercial sector excluding revolving home equity loans.

- Commercial and Industrial Loans (Business Loans): Commercial and industrial loans at all Commercial Banks.

- Consumer Loans: Consumer (Individual) loans at all commercial banks.

- Gross Domestic Product (GDP), Personal Consumption Expenditures (PCE), Aggregate of gross private domestic investment (Non-RESI), Residential gross private domestic investment (RESI), and the Price Indexes for private residential Investment (PRESI) are all from the National Income and Product Accounts Tables (NIPA) at the Bureau of Economic Analysis.

- To calculate the implied markup, $\bar{s}$, we used the house price index (HPI), residential investment (RESI) and the price for the RESI (PRESI).

- We use the equation $p_{h t}=\zeta^{-1} y_{d t}^{1-\zeta} p_{d t} \bar{s}_{t}$.

- House Price Index (HPI): Constructed based on conventional conforming mortgage transactions obtained from the Federal Home Loan Mortgage Corporation(Freddie Mac) and the Federal National Mortgage Association (Fannie Mae).

- Source: The Office of Federal Housing Enterprise Oversight (OFHEO).

Risk Premium: To calculate our risk premium, we used the spread between the prime rate and the three month commercial paper. These data can be obtained from Federal Reserve Bank of St. Louis, FRED Dataset under the category of Interest Rates.

- http://research.stlouisfed.org/fred2/categories/22. These two series are monthly.

- Commercial rate: CP3M, 3-Month Commercial Paper Rate: 1971-04 till 1997-08.

- Prime rate: MPRIME, Bank Prime Loan Rate: 1949-01 till 2009-08.

\section{B.1. Data sources}

\section{B.1.1. Calibration of production technology parameters}

We use mostly the same methodology as in Davis and Heathcote (2005). However, because BEA NIPA tables switched from SIC to NAICS classification, we use now NAICS data when possible. Also, for house price index $P_{h}$ we use FHFA HPI instead of Freddie Mac's CMHPI. All the NIPA table annual data are available for the period of 19482010. The quarterly house price index is available for the period 1975-2010. To obtain annual values, we average it over each year.

According to Davis and Heathcote (2005): (1) all the end-year stock variables are adjusted to the middle-of-year values using geometric mean smoothing, e.g. for period $t$ capital stock we use $\sqrt{K_{t-1} K_{t}}$; (2) $i_{c}=G P D I-R I+G N I-S L I$; (3) the empirical estimate of capital share $\theta_{b}$ is obtained from the time series of $V A_{b}, W_{b}, P I_{b}$ and $T A X_{b}$ (see Table 1 ) using the formulas:

$$
\theta_{b, t}=1-\frac{W_{b, t}}{V A_{b, t}-P I_{b, t}-T A X_{b, t}}, \quad \theta_{b}=\frac{1}{T} \sum_{t=1}^{T} \theta_{b, t}
$$

and the values of $\theta_{m}$ and $\theta_{s}$ are calculated using similar relations.

We take natural logarithms of all variables. Sources are from the NIPA: Bureau of Economic Analysis www.bea.gov; FHFA: Federal Housing Finance Agency www.fhfa.gov/Default.aspx?Page=87. 
Description of variables

Var Tables/rows

GDP NIPA GDP \& Personal Income: 1.1.3. Real Gross Domestic Product, Quantity Indexes: 1. Gross domestic product

PCE NIPA GDP \& Personal Income: 1.1.3. Real Gross Domestic Product, Quantity Indexes: 2. Personal consumption expenditures

$i_{c} \quad$ NIPA GDP \& Personal Income: 1.1.3 Real Gross Domestic Product, Quantity Indexes, 1.1.5 Gross Domestic Product, GPDI: 7.Gross private domestic investment, RI: 12. Gross private domestic investment - Residential; NIPA GDP \& Personal Income: 3.9.3, 3.9.5 Government Consumption Expenditures and Gross Investment, GNI: 18. Federal - Nondefence - Gross investment, SLI: 23. State and local - Gross investment

$y_{d} \quad$ RI: NIPA GDP \& Personal Income: 1.1.3 Real Gross Domestic Product, 1.1.5 Gross Domestic Product: 12. Gross private domestic investment Residential

$P_{d} \quad$ NIPA GDP \& Personal Income: 1.1.3 Real Gross Domestic Product, 1.1.5 Gross Domestic Product, 12. Gross private domestic investment/ Residential

$P_{c} \quad$ NIPA GDP \& Personal Income: 1.1.3 Real Gross Domestic Product, 1.1.5 Gross Domestic Product, 2. Personal consumption expenditures

$P_{h} \quad$ FHFA HPI (All-transactions Index, U.S. and Census Divisions)

$K \quad$ NIPA Fixed Assets: 1.1 Current-Cost Net Stock of Fixed Assets and Consumer Durable Goods, 1.2 Chain-Type Quantity Indexes for Net Stock of Fixed Assets and Consumer Durable Goods; $K_{p r}$ : 4. Fixed Assets - Private - Nonresidential; $K_{\text {gov }}$ : 9. Fixed Assets - Government - Nonresidential

$h \quad$ NIPA Fixed Assets: 1.1 Current-Cost Net Stock of Fixed Assets and Consumer Durable Goods: 7. Fixed Assets - Private - Residential

$x_{b} \quad$ NIPA GDP-by-industry: Value Added by industry, Chain-Type Quantity Indexes for Value Added by industry

$k_{b} \quad$ NIPA Fixed Assets: 3.1 ES Current-Cost Net Stock of Private Fixed Assets by Industry, 3.2 ES Chain-Type Quantity Indexes for Net Stock of Private Fixed Assets by Industry

$n_{b} \quad$ NIPA GDP \& Personal Income: 6.9 B,C,D Hours Worked by Full-Time and Part-Time Employees by Industry

$\mathrm{PI}_{b} \quad$ GDP \& Personal Income: 6.12 B,C,D. Nonfarm Proprietors' Income by Industry

$V A_{b} \quad$ GDP-by-Industry: Value Added by industry

$W_{b} \quad$ GDP-by-Industry: 1948-1986 (SIC): GDPbyInd_VA_SIC.xls: 1987-2010 (NAICS): Components of Value Added by Industry: Compensation of employees

$\mathrm{TAX}_{b}$ GDP-by-Industry: 1948-1986 (SIC): GDPbyInd_VA_SIC.xls: 1987-2010 (NAICS): Components of Value Added by Industry: Taxes on production and imports less subsidies

We do not include in the table above variables for manufacturing $\left(x_{m}, k_{m}, n_{m}, \theta_{m}\right)$ and services $\left(x_{s}, k_{s}, n_{s}, \theta_{s}\right)$ intermediate industries, because the correspondent columns replicate those for building $\left(x_{b}, k_{b}, n_{b}, \theta_{b}\right)$. Here, Building $\left(x_{b}, k_{b}, n_{b}, \theta_{b}\right)$ includes branches: (1) Construction; Manufacturing $\left(x_{m}, k_{m}, n_{m}, \theta_{m}\right)$ includes branches: (1) Agriculture, forestry, fishing, and hunting; (2) Mining; (3) Manufacturing; and Services $\left(x_{s}, k_{s}, n_{s}, \theta_{s}\right)$ includes branches: NAICS: (1) Utilities; (2) Wholesale trade; (3) Retail trade; (4) Transportation and warehousing; (5) Information; (6) Professional and business services; (7) Management of companies and enterprises; (8) Administrative and waste management services; (9) Educational services, health care, and social assistance; (10) Arts, entertainment, recreation, accommodation, and food services; (11) Other services, except government. SIC: (1) Transportation and public utilities; (2) Wholesale trade; (3) Retail trade; (4) Services.

\section{B.1.2. Data used to construct risk shocks}

Description of variables

\begin{tabular}{|c|c|c|}
\hline Variable & $\begin{array}{l}\text { Name in } \\
\text { WRDS }\end{array}$ & Description [1] \\
\hline Backlog & hbbck & $\begin{array}{l}\text { This is the dollar value of housing units subject to pending sales contracts at the end of the period. This item } \\
\text { includes: } 1 \text {. Backlog } 2 \text {. Outstanding contracts at period end } 3 \text {. Consolidated company amounts } 4 \text {. Homes in } \\
\text { contract backlog } 5 \text {. Backlog of uncompleted contracts This item excludes: } 1 \text {. Unconsolidated subsidiary } \\
\text { amounts } 2 \text {. Closings } 3 \text {. Deliveries } 4 \text {. Settlements }\end{array}$ \\
\hline $\begin{array}{l}\text { Total Homebuilding } \\
\quad \text { Inventories }\end{array}$ & hbinvt & $\begin{array}{l}\text { This item includes: } 1 \text {. Deposits for land } 2 \text {. Consolidated inventory not owned } 3 \text {. All other homebuilding-related } \\
\text { inventory This item excludes inventories related to the mortgage banking business, such as mortgages held for } \\
\text { sale. }\end{array}$ \\
\hline $\begin{array}{l}\text { Undeveloped } \\
\text { Inventories-Owned }\end{array}$ & hbinvuo & $\begin{array}{l}\text { This item includes: } 1 \text {. Land held for development 2. Manufacturing materials and other 3. Other Land and land } \\
\text { options held for future development or sale This item excludes: } 1 \text {. Land deposits } 2 \text {. Land inventory not owned }\end{array}$ \\
\hline $\begin{array}{l}\text { Land Under } \\
\text { Development }\end{array}$ & hbinvlud & $\begin{array}{l}\text { This item includes: 1. Land under development 2. Land and land under development 3. Homesites and land } \\
\text { under development This item excludes: } 1 \text {. Land held for development and sale } 2 \text {. Construction in progress }\end{array}$ \\
\hline
\end{tabular}

Source: Compustat Manuals and Overviews-General-Compustat Online Manual: http://wrds-web.wharton.upenn.edu/wrds/support/Data/_001Manuals and Overviews/_001Compustat/_001General/_000dataguide/index.cfm

\section{References}

Aoki, Kosuke, Proudman, J., Vlieghe, J., 2004. House prices, consumption, and monetary policy: a financial accelerator approach. J. Financ. Intermed. 13 (4), 414-435.

Bachmann, R., Elstner, S., Sims, E., 2013. Uncertainty and economic activity: evidence from business survey data. Am. Econ. J.: Macroecon. 5 (2), $217-249$. Bloom, N., Floetotto, M., Jaimovich, N., 2008. Really uncertain business cycles. Stanford University Working Paper. 
Burns, A.F., Mitchell, W.C., 1946. Measuring business cycles. Studies in Business Cycles, No. 2. NBER, New York.

Carlstrom, C.T., Fuerst, T.S., 1997. Agency costs, net worth, and business fluctuations: a computable general equilibrium analysis. Am. Econ. Rev. 87, 893-910. Carlstrom, C.T., Fuerst, T.S., 1998. Agency costs and business cycles. Econ. Theory (12), 583-597.

Christiano, L., Eichenbaum, M., Evans, C., 2005. Nominal rigidities and the dynamic effects of a shock to monetary policy. J. Polit. Economy 113 (1), 1-45. Christiano, L., Motto, R., Rostagno, M., 2013. Risk shocks. NBER Working Paper No. 18682.

Chugh, S.K., 2011. Firm risk and leverage-based business cycles. University of Maryland Department of Economics Working Paper.

Davis, Morris, Heathcote, J., 2005. Housing and the business cycle. Int. Econ. Rev. 46 (3), 751-784.

Dorofeenko, V., Lee, G., Salyer, K., 2008. Time varying uncertainty and the credit channel. Bull. Econ. Res. 60 (4), $375-403$.

Fernández-Villaverde, J., Guerrón-Quintana, P.A., Rubio-Ramirez, J., Uribe, M., 2011. Risk matters: the real effects of volatility shocks. Am. Econ. Rev. 101 (6), $2530-2561$.

Fisher, J.D.M., 2007. Why does household investment lead business investment over the business cycle? J. Polit. Economy 115, 141-168.

Gilchrist, S., Sim, J., Zakrajsek, E., 2008. Uncertainty, credit spreads, and investment dynamics. FRB Working Paper.

Glaeser, E.L., Gyourko, J., 2006. Housing dynamics. NBER Working Paper No. 12787.

Greenwood, J., Hercowitz, Z., Krusell, P., 2000. The role of investment specific technological change in the business cycle. Eur. Econ. Rev. 44, 91-115.

Iacoviello, M., 2005. House prices, borrowing constraints and monetary policy in the business cycle. Am. Econ. Rev. 95 (June (3)), $739-764$.

Iacoviello, M., Minetti, R., 2008. The credit channel of monetary policy: evidence from the housing market. J. Macroecon. $30,69-96$.

Iacoviello, M., Neri, S., 2010. Housing market spillovers: evidence from an estimated DSGE model. Am. Econ. J.: Macroecon. 2 (2), $125-164$.

Iacoviello, M., 2013. Financial business cycles. Boston College Economics Department Working Paper.

Kahn, J.A., 2008. What drives housing prices. New York Federal Reserve Staff Report No. 345. 